University of Wollongong

Research Online

Faculty of Engineering and Information

Faculty of Engineering and Information

Sciences - Papers: Part B

Sciences

2018

Effect of Geogrid Reinforcement on the Flexural Behaviour of Concrete Pavements

Abbas Sahib Abd-Ali Al-Hedad

University of Wollongong, asaa774@uowmail.edu.au

Muhammad N. S Hadi

University of Wollongong, mhadi@uow.edu.au

Follow this and additional works at: https://ro.uow.edu.au/eispapers1

Part of the Engineering Commons, and the Science and Technology Studies Commons

Research Online is the open access institutional repository for the University of Wollongong. For further information contact the UOW Library: research-pubs@uow.edu.au 


\title{
Effect of Geogrid Reinforcement on the Flexural Behaviour of Concrete Pavements
}

\author{
Abstract \\ This paper presents results of an investigation of the effect of geogrid reinforcement on the flexural \\ behaviour of concrete pavements. Six concrete slab specimens having dimensions of $900 \times 900 \times 60 \mathrm{~mm}$ \\ were prepared and tested. Three of the specimens were unreinforced and taken as references. The other \\ three were reinforced with a triaxial geogrid layer located at $40 \mathrm{~mm}$ from the top of the specimen. To \\ support the specimens during the testing, two layers of recycled rubber having a side dimension of \\ $900 \mathrm{~mm}$ and a $60 \mathrm{~mm}$ total thickness were used. According to the location of the applied load, the \\ specimens were divided into three groups. Each group included two specimens (unreinforced and \\ reinforced specimen). The specimens of the first group were tested by applying a load at the corner of the \\ specimen. For the second group, the specimens were tested by applying a load at the edge of the \\ specimen. The load was applied at the interior of the specimens for the third group. The monotonic test \\ load was applied at a rate of $0.25 \mathrm{~mm} / \mathrm{min}$. Study parameters investigated in this study included the \\ ductility, fracture energy and formation of cracks of the specimens. Test results obtained indicate that the \\ flexural performance and cracking resistance of the concrete slab specimens reinforced with the geogrid \\ can be improved.

\section{Disciplines} \\ Engineering | Science and Technology Studies

\section{Publication Details} \\ Al-Hedad, A. S. A. \& Hadi, M. N. S. (2019). Effect of Geogrid Reinforcement on the Flexural Behaviour of \\ Concrete Pavements. Road Materials and Pavement Design, 20 (5), 1005-1025.
}




\title{
Effect of Geogrid Reinforcement on the Flexural Behaviour of Concrete Pavements
}

\author{
Abbas S. A. Al-Hedad ${ }^{1}$; and Muhammad N. S. Hadi ${ }^{2}$ \\ ${ }^{1}$ School of CME Engineering, University of Wollongong, Wollongong, NSW 2522, Australia. \\ E-mail: asaa774@uowmail.edu.au \\ ${ }^{2}$ Associate Professor, School of CME Engineering, University of Wollongong, Wollongong, \\ NSW 2522, Australia (corresponding author).E-mail: mhadi@uow.edu.au
}


1 Effect of Geogrid Reinforcement on the Flexural Behaviour of Concrete

\section{Abstract}

4 This paper presents results of an investigation of the effect of geogrid reinforcement on the

5 flexural behaviour of concrete pavements. Six concrete slab specimens having dimensions of $6900 \times 900 \times 60 \mathrm{~mm}$ were prepared and tested. Three of the specimens were unreinforced and 7 taken as references. The other three were reinforced with a triaxial geogrid layer located at 40 $8 \mathrm{~mm}$ from the top of the specimen. To support the specimens during the testing, two layers of 9 recycled rubber having a side dimension of $900 \mathrm{~mm}$ and a $60 \mathrm{~mm}$ total thickness were used. 10 According to the location of the applied load, the specimens were divided into three groups.

11 Each group included two specimens (unreinforced and reinforced specimen). The specimens of the first group were tested by applying a load at the corner of the specimen. For the second group, the specimens were tested by applying a load at the edge of the specimen. The load was applied at the interior of the specimens for the third group. The monotonic test load was applied at a rate of $0.25 \mathrm{~mm} / \mathrm{min}$. Study parameters investigated in this study included the ductility, fracture energy and formation of cracks of the specimens. Test results obtained indicate that the flexural performance and cracking resistance of the concrete slab specimens reinforced with the geogrid can be improved.

Author Keywords: Triaxial geogrid, Portland cement concrete pavements, Corner loading, Edge loading, Interior Loading, Bending stresses 


\section{Introduction}

Portland cement concrete pavements are mostly reinforced with traditional steel mesh or bars to provide the strength required to resist stresses caused by traffic loads. Although steel reinforcement provides a basic strengthening for concrete pavements, there are still few limitations restraining their use (Tang et al., 2008). Such restraints include construction limitations related to placing reinforcing steel bars in thin sections such as concrete pavement overlays or resurfacing and related to chemical limitations such as concerns of steel corrosion. In addition, alternative reinforcement materials such as fibre reinforced polymer bars, tendons and grids are on the rise as alternatives to steel reinforcement (Tang et al., 2008).

Because of these limitations, several studies conducted for concrete elements reinforced with fibres such as steel, polypropylene, glass and nylon (Sorelli et al., 2006; Gupta et al., 2008; Boscato \& Russo, 2009; Rajeshkumar et al., 2010; Salehian et al., 2014; Yoo et al., 2015; Karahan et al., 2016). These studies illustrated that the fibre could enhance the ductility and the cracking resistance of concrete. For the concrete pavement application, several concerns that make using the fibers as the reinforcement materials are unfeasible. For example, during mixing the concrete ingredients with the fibers, it cannot easily get a uniform mixture. Also, the workability of fiber reinforced concrete mixture still concerns for contractors, especially at high fiber volume.

Geogrid products which are considered one of the geosynthetic products are mainly used for strengthening subgrade and subbase layers beneath the pavements (Ling \& Liu, 2001; Shanker \& Suresha, 2006; Tang et al., 2008; Abu-Farsakh \& Chen, 2011; Abu-Farsakh, Akon, \& Chen, 2016). Also, several experimental and theoretical studies have been conducted on asphalt pavements reinforced with the geogrid. They include Khodaii and Fallah (2004); Doh, Baek, and Kim (2009); Sobhan and Tandon (2011); Abdesssemed, Kenai, and Bali (2015) and Zofka, Maliszewski, and Maliszewska (2016). These studies proved that the 
geogrid could improve the ductile post-cracking behaviour and loading capacity of the pavements.

Geogrid products have several structural advantages making them a potential alternative of steel reinforcement for Portland cement concrete thin sections under relatively light loading conditions (Tang et al., 2008; and Arulrajah et al., 2014). These advantages include a high tensile strength and excellent chemical resistance. Also, the geogrid can provide further shear strength at the interface between the geogrid and the surrounding materials (Meski \& Chehab, 2014; Siva \& Agarwal, 2014, 2015a, 2015b; Wang et al. 2015; and Abdesssemed et al. 2015). Siva and Agarwal $(2014,2015 a)$ investigated the behaviour of prismatic and cylindrical specimens confined with one or two geogrid layers. Wang, Sheikh, and Hadi (2015) also studied the deformation capacity of cylindrical specimens confined with one, two and three polymer grid layers. They concluded that the geogrid could increase the compressive and flexural strength of concrete, along with the resistance of crack propagation which can be improved.

The failure modes in term of formation of cracks in the Portland cement concrete pavements are different in comparison with other kinds of concrete elements. The concrete pavements have a wide surface area subjected daily to the fluctuation of the traffic and environmental effects. These effects often lead to cracking of concrete. As a result, the performance of 64 concrete pavements is eventually degraded. In addition, the conditions of applied loads (traffic loads) and support of concrete pavements have a different impact on the failure modes created in the concrete. From these points, 67 however, studying the behaviour of concrete pavements reinforced with the geogrid requires more investigation. 
69 For economic reasons, the Australian market shows that the cost of manufacture and

70 installation of the geogrid products is cheaper than the traditional reinforcement materials.

71 There is no need for extra cost for transporting and tying the geogrid ribs like the steel bars.

72 So, the cost of supply and placement of the geogrid materials are often lower than the cost of 73 traditional reinforcement.

\section{$74 \quad 2$. Objective of the study}

75 This study on geogrid reinforcement for Portland cement concrete focuses on the flexural 76 performance of concrete pavements through preparing six concrete slab specimens tested

77 under a monotonic load. A single layer of triaxial geogrid placed in the concrete specimens to 78 provide tensile reinforcement in flexure. The ductility of specimens is the main study parameter, along with formation of cracks which were monitored and evaluated.

\section{Properties of triaxial geogrid}

81 The triaxial geogrid which is one of the geosynthetic products was selected as a flexural 82 reinforcement layer in this study. This is because their openings' shape can provide the appropriate interlocking between the geogrid layer and the surrounding concrete. In addition, the triaxial geogrid proved that the tensile and shear strengths of concrete elements reinforced with this type of geogrid were improved in comparison with other geogrid types (Meski \& Chahab, 2014; Arulrajah et al., 2014).

87 The triaxial geogrid used in this study was made from polypropylene composite materials 88 (Maxwell, Kim, Edil, \& Benson, 2005). This product has triangular openings with a multidirectional structure. The ribs of the triaxial geogrid are connected at one point called node.

90 The midrib depth and width of the ribs were $1.53 \mathrm{~mm}$ and $1.55 \mathrm{~mm}$, respectively, with the 91 length of $34 \mathrm{~mm}$. 
In this study, two triaxial geogrid samples, which were differed in the direction of alignment of the ribs with respect to the direction of tensile test load, were prepared and tested. They were a Machine Direction sample (Sample MD) where the geogrid ribs are parallel to the direction of the tensile test load, Figure 1 (a), and a Cross Machine Direction sample (Sample CMD) where the geogrid ribs are perpendicular to the direction of the tensile test load, Figure $1(b)$.

The mechanical properties of the triaxial geogrid samples were determined using Australian Standards (AS) 3704:2005 and European Standard (EN ISO) 10319:1996. All tests were conducted at the laboratories of the School of Civil, Mining and Environmental Engineering, University of Wollongong (UOW), Australia. The Instron 500-kN tension testing machine (Model of 8033) was used to test the geogrid samples.

Two clamps made from steel plates were fabricated to clamp the samples during the testing. These clamps were fixed together with the geogrid samples using 12 bolts having a size of $13 \mathrm{M}$, as shown in Figure 2.

All geogrid samples were prepared according to the EN ISO 10319:1996 Standard. The length of Sample MD, which is defined as the initial distance between two reference points located on the sample parallel to the tensile test load, was $185 \mathrm{~mm}$ and for Sample CMD was 130 mm. The width of Samples MD and CMD was $275 \mathrm{~mm}$ and $250 \mathrm{~mm}$, respectively.

Table 1 and Figure 3 present the test results of the triaxial geogrid samples. For Sample MD, the maximum tensile load was $5.2 \mathrm{kN}$, and the corresponding strain was $9.8 \%$. For the same sample, the tensile strength per unit width was $18.82 \mathrm{kN} / \mathrm{m}$. For Sample CMD, the maximum tensile load was $6.5 \mathrm{kN}$, and the corresponding strain was $13.34 \%$. The tensile strength per unit width was $26.11 \mathrm{kN} / \mathrm{m}$. 
115 Secant stiffness which is defined as the ratio of the tensile strength per unit width to the

116 corresponding strain at a specified point on the curve was determined. The secant stiffness at $11710 \%$ of strain for Sample MD was $2.62 \mathrm{kN} / \mathrm{m} / \mathrm{strain} \%$, and for Sample CMD was 2.20

$118 \mathrm{kN} / \mathrm{m} / \mathrm{strain} \%$. It can be seen that there are differences in the test results of the triaxial geogrid 119 between Samples MD and CMD. This demonstrates the importance of the placing direction of 120 triaxial geogrid when it is applied in the field.

\section{4. Experimental program}

122

123

\section{1 test matrix}

Table 2 and Figure 4 present the details of the test matrix and the configurations of unreinforced and geogrid reinforced concrete specimens. Six concrete slab specimens were prepared and tested under a monotonic load. One specimen was tested for each loading position. The number of specimens selected in this study is to simulate the test conditions of study conducted by Hammons (1998). He investigated the behaviour of concrete pavements with one specimen for each case of the loading positon with keeping the side dimension to thickness ratio greater than 15 .

Monotonic loading was selected for testing the specimens. This is it is in line with findings Hammons (1998), where monotonic loading is recommended for thin sections. In addition, several experimental studies, which aimed to study the behaviour of concrete pavements under cyclic loads, were conducted with concrete specimens having a thickness of more than $150 \mathrm{~mm}$ (Graff et al. 2012 and Breitenbuech and Kunz 2013).

The specimens were tested at a rate of $0.25 \mathrm{~mm} / \mathrm{min}$. This rate was selected to correspond to the deflection that occur at the loaded area of a plain concrete pavement having a side dimension to thickness ratio greater than or equal to 15 and subjected to a load of $20 \mathrm{kN}$ (Austroads 2004). This ratio is satisfied with the field dimensions of rigid pavements listed in 
139 Austroads (2004) for a thickness of concrete pavements ranging between 125 to $180 \mathrm{~mm}$ and

140 a side dimension between 1875 to $2700 \mathrm{~mm}$. Also, the ratio is in line with conducted studies

141 achieved by Hammons (1998) and Ruiz-Ripoll et al. (2016).

142 In addition, the test load process adopted here complied with the design assumptions of 143 concrete pavements adopted by Portland Cement Association (Hammons, 1998).

144 According to the location of the applied load, the specimens were divided into three groups.

145 Each group included two specimens (unreinforced and reinforced specimen). The specimens

146 of the first group were tested by applying the load at the corner of the specimen, along the

147 corner bisector, as shown in Figure 9 (a) and (d). For the second group, the specimens were

148 tested by applying the load at the edge of the specimen. The load was applied at the interior of

149 the specimens for the third group.

150 All specimens had the dimensions of $900 \times 900 \times 60 \mathrm{~mm}$. These dimensions were adopted to 151 mimic as much as possible the flexural behaviour of concrete pavements and also to be 152 suitable for testing conditions available in the laboratory.

153 The concrete slab with a thickness of $60 \mathrm{~mm}$ was selected after many calculations made using 154 Westergaard's formulae (Haung 2004) within uncracked concrete conditions. A single tyre 155 load of $20 \mathrm{kN}$ was adopted. The field dimensions of the concrete pavement were adopted 156 from the design requirements of rigid pavement which are reported by Austroads (2004). The 157 dimensions of slab specimens that were selected and tested in this study were $900 \times 900 \times 60$ $158 \mathrm{~mm}$.

159 Three of the specimens were unreinforced and taken as references. The other three specimens 160 were reinforced with a triaxial geogrid layer located at $40 \mathrm{~mm}$ from the surface of specimens. 161 The location of the geogrid layer was selected to be within the tension zone of the slab 162 specimen. In this study, the tension zone was below the neutral axis, which is $30 \mathrm{~mm}$ below 
163 the surface. Also, providing a $20 \mathrm{~mm}$ concrete cover under the geogrid layer is adequate for 164 aggregates with a maximum size of $10 \mathrm{~mm}$.

165 Placing the geogrid at $40 \mathrm{~mm}$ below the surface is correct for the edge and interior loading 166 position. For the corner loading position, the tension zone of the concrete slab generates at the 167 upper part of the slab. Keeping the geogrid layer at same location was to simulate to what 168 practically happens in the field. In which the geogrid reinforcement layer is placed at the same 169 level of the rigid pavements for all kinds of loading.

170 The labelling of unreinforced and geogrid reinforced concrete specimens are summarised in

171 Table 2. The first letter in the label is Unreinforced concrete specimens (U) (references) and

172 Geogrid reinforced concrete specimens $(\mathrm{G})$. The second letter in the label refers to the 173 location of the applied load, which are: Corner, Edge, and Interior, labelled as "C", "E", and 174 "I", respectively. For example, Specimen GC refers to the specimen which was reinforced 175 with the triaxial geogrid and tested by applying a load at the corner of the specimen.

176 Two layers of recycled rubber having the dimensions of $900 \mathrm{~mm}$ by $900 \mathrm{~mm}$ with a $60 \mathrm{~mm}$ 177 total thickness were used to support the specimens during the testing. This is to simulate the 178 subbase layer. Figure 5 shows the dimensions of the recycled rubber.

\subsection{Preparation of timber formworks and steel testing box}

180 Six timber formworks were prepared in this study for moulding the concrete slab specimens,

181 as shown in Figure 6. The inside dimensions of formworks were $900 \times 900 \times 60 \mathrm{~mm}$.

182 For reinforced specimens, the walls of the formworks consisted of two parts: bottom and top 183 part. As shown in Figure 6 (b), the height of the bottom part was $20 \mathrm{~mm}$, and the height of the 184 top part was $40 \mathrm{~mm}$. The walls and the geogrid layer were fixed together using 16 bolts and 185 screws. 
186 A steel box was designed and fabricated in this study to support the subbase and the concrete

187 specimens during the testing. This box was made from steel plates and had inside dimensions 188 of $900 \times 900 \times 120 \mathrm{~mm}$. The walls of the box were made from steel plates and had a cross 189 sectional area of $8 \times 120 \mathrm{~mm}$. The base of the testing box had the dimensions of $916 \times 916 \times$

$1906 \mathrm{~mm}$. Two opposite walls were welded to the base. The other two opposite walls were fixed 191 using eight 13M bolts and nuts. Figure 7 shows a photo of the steel testing box and details of 192 its dimensions.

\subsection{Casting and curing specimens}

194 All specimens were cast on the same day using ready-mixed concrete. The concrete was mix

195 with Ordinary Portland cement (Type general purpose), crushed stone aggregates (maximum 196 size of $10 \mathrm{~mm}$ ) and coarse and fine sand.

197 The concrete was also mixed with two kinds of supplementary cementitious materials, which 198 were fly ash and ground granulated blast-furnace slag (GGBS). To provide adequate 199 workability for the mix, a water-reducing admixture (WRDA-PN20) was added. The water to 200 cement ratio adopted in this concreter mixture was 0.45 . Table 3 lists details of the concrete 201 ingredients.

202 A table vibrator was used to compact the concrete inside the timber formworks, with a 203 frequency of $50 \mathrm{~Hz}$. This technique had successfully achieved the purpose by providing a 204 uniform thickness of concrete surrounding the geogrid layer. This was proved through 205 checking the bottom surface of the reinforced specimens visually before the test and 206 measuring the thickness of the concrete cover after the test, as shown in Figure 8.

207 The specimens were cured after 24 hrs from the casting and continued for 28 days. The curing process was conducted by gathering all the specimens at the same place in the laboratory. 
209 This was to guarantee that the specimens were being exposed to the same environmental 210 curing conditions.

211 During the curing process, the specimens were covered with two hessian blankets to prevent

212 or reduce losing moisture from the concrete. In addition, two layers of plastic sheets were 213 used to cover the specimens. This was to minimise the influences of ambient air. The 214 specimens with the hessian covers were wetted using clean water until the curing time 215 finished.

\section{$216 \quad 4.4$ Preparation of specimens for testing}

217 The configuration of the specimens prepared for testing is shown in Figure 9 (a) to (c). Linear 218 Variable Displacement Transducers (LVDTs) were used to measure the deflection of the 219 specimens at the specified positions, as shown in Figure 9 (d) to (f). These positions were 220 selected to monitor the behaviour of specimens during the testing.

221 In total, 22 LVDTs were used. For the specimens where the load was applied at the corner, 222 four LVDTs were installed and placed alongside the loading position. The first one $\left(\mathrm{L}_{1}\right)$ was 223 located at a distance of $200 \mathrm{~mm}$ from the edge of the specimen. The remaining three LVDTs 224 were distributed at $145 \mathrm{~mm}$ along the side of the specimens. In addition, two LVDTs were 225 installed at the two other corners, at a distance of $100 \mathrm{~mm}$ from each edge of the specimen, as 226 shown in Figure 9 (d).

227 For the specimens which were tested under the edge loading, six LVDTs were used and 228 placed at two crossing lines, closer to the loading position. The LVDT $\mathrm{L}_{4}$ was located at a 215 $229 \mathrm{~mm}$ distance from the loading edge of the specimen. The other LVDTs were positioned at the 230 spacing, between 120 to $155 \mathrm{~mm}$, as shown in Figure 9 (e). Also, two additional LVDTs were 231 placed at the further two corners, at a $100 \mathrm{~mm}$ distance from the edge of the specimen. 
232 Six LVDTs were placed at a straight line close to the loading position for the third specimens 233 tested under interior loading. The LVDT $\mathrm{L}_{1}$ was located at $120 \mathrm{~mm}$ from the edge of the 234 specimen. The distances between the LVDTs were $100 \mathrm{~mm}$. In addition, two LVDTs were 235 placed at the other corners, at a distance of $100 \mathrm{~mm}$ from the specimen's edge, as shown in 236 Figure 9 (f). All LVDTs were clamped using two square hollow steel bars held by two G237 clamps.

238 Two layers of recycled rubber each having a thickness of $30 \mathrm{~mm}$ and a side dimension of 900 $239 \mathrm{~mm}$ were used to support the concrete specimens during the testing. These layers were placed 240 inside the test box followed by the concrete slab without any bonding, as shown in Figure 10.

241 The modulus of subgrade reaction $(\mathrm{k})$ of the recycled rubber was required for calculating the 242 bending stresses of the specimens. This was determined by testing a sample of recycled 243 rubber having a surface area of $152 \times 152 \mathrm{~mm}$ with a thickness of $24 \mathrm{~mm}$. The instron testing 244 machine (Model of 8033) was used to conduct this test. During the testing, the compressive 245 applied loads with the corresponding displacements were recorded. According to the test 246 results, the modulus of subgrade reaction of the recycled rubber was $60 \mathrm{MPa} / \mathrm{m}$.

247 The compressive strength of concrete was determined by testing three standard cylinders 248 having a diameter of $100 \mathrm{~mm}$ and a height of $200 \mathrm{~mm}$. These tests were carried out at the age 249 of 28 days of concrete. The average compressive strength of concrete was $29 \mathrm{MPa}$. Based on 250 AS 3600 (2009) and for the normal strength concrete, the Poisson's ratio and modulus of 251 elasticity of the concrete were assumed to be 0.2 and $25.83 \mathrm{GPa}$, respectively.

252 The flexural strength of concrete was also calculated by testing three concrete prisms having 253 the dimensions of $150 \times 150 \times 500 \mathrm{~mm}$ at the age of 28 days (AS 1012.11:2000). These tests 254 showed that the flexural strength of concrete was $4.28 \mathrm{MPa}$. 
255 During the testing, four steel strips were fixed around the perimeter of the testing box. This is 256 to support the concrete slab. These strips had a cross section area of $3 \times 8 \mathrm{~mm}$ with a length of $257900 \mathrm{~mm}$, as shown in Figure 9.

258 High strength plaster was used for capping the position of the loading of the specimen surface 259 with a circular area of a $140 \mathrm{~mm}$ diameter. This material helps in providing a smooth level 260 surface for the face of the loading piston. Thus, this ensures the stresses will be distributed 261 uniformly.

262 The surface of the specimens was marked through drawing straight lines in two directions. 263 This facilitated monitoring and evaluating the cracks that formed in the specimen. Four G264 clamps were used to completely fix the steel testing box with the supports during applying the 265 load. All the LVDTs lead wires were connected to the computer to record the deflections 266 during the testing. A circular steel desk having a $140 \mathrm{~mm}$ diameter was prepared and placed 267 between the piston of the testing machine and the specimen.

\section{5. Experimental results and discussion}

\section{$269 \quad 5.1$ Test results}

270 All concrete slab specimens were tested by applying a displacement controlled load at a rate 271 of $0.25 \mathrm{~mm} / \mathrm{min}$. The $2.5 \mathrm{~mm}$ of surface crack width which was measured by a standard ruler 272 edge with an accuracy of $0.5 \mathrm{~mm}$ was considered as the failure criterion (O'Flaherty 2005). 273 This criterion was adopted to provide enough time for monitoring formation of cracks in the 274 concrete specimens during the testing.

275 Table 4 presents the test results of unreinforced and geogrid reinforced concrete specimens. In 276 this table, the total applied load of unreinforced specimens $\left(\mathrm{P}_{\text {ref. }}\right)$ and reinforced specimens $277\left(\mathrm{P}_{\mathrm{AL}}\right)$ are presented. Also, the deflections of unreinforced specimens $\left(\Delta_{\text {ref. }}\right)$ and reinforced 278 specimens $\left(\Delta_{\mathrm{AL}}\right)$ occurred at the centre of the loaded area are listed in this table. In this study, 
the positive sign was assumed when the slab is deflected downwards. While the negative sign

280 is assumed when the slab is deflected upwards.

281 The increase of load-carrying capacity of the reinforced specimens compared with the

282 unreinforced specimens was calculated using the expression of $\left[\left\{\left(\mathrm{P}_{\mathrm{AL}} / \mathrm{P}_{\mathrm{ref} .}\right)-1\right\} \times 100\right]$, as shown 283 in Table 4.

284 The ductility of the tested concrete specimens is one of the investigated parameters in this 285 study. It is defined as the ability of the specimen to resist the applied load from the start of 286 loading until a $2.5 \mathrm{~mm}$ surface crack width occurred. It was determined by calculating the 287 area under the applied load versus the deflection curve (Figure 11), as listed in Table 4.

288 The fracture energy, which is defined as the energy required to form the microcracks in the 289 concrete, was calculated according to Bažant and Kazemi (1990). In this study, the fracture 290 energy was determined per slab thickness of $60 \mathrm{~mm}$ per unit extension of the crack length for 291 the edge and interior loading position, as shown in Figures 14 and 17. It was determined by 292 considering the area of the applied load versus displacement curve as the required fracture 293 energy before cracking the concrete.

294 The evaluation of these findings is discussed, along with the observation of initiation and 295 propagation of cracks.

\subsection{Corner loading}

297 Figure 11 (a) presents the curves of corner applied load versus deflection that occurred at the 298 centre of the loaded area for Specimens UC and GC. During the load application, the 299 maximum applied load of Specimen UC (reference) was $17 \mathrm{kN}$, as listed in Table 4. While for 300 Specimen GC, the total load was $20 \mathrm{kN}$. This achieved an increase in the ductility for 301 Specimen GC by about $10 \%$ more than the reference specimens. 
302 Figure 12 shows the deflection profiles and crack map of Specimens UC and GC, along

303 LVDTs $\mathrm{L}_{1}$ through $\mathrm{L}_{4}$. The maximum deflection that occurred for Specimen UC was $8 \mathrm{~mm}$ at 304 a distance of $200 \mathrm{~mm}$ from the edge of the specimen. While for Specimen GC, the maximum 305 deflection was $6.5 \mathrm{~mm}$ at the same location.

306 Upward deflection took place during the testing of Specimen UC. This means that the surface 307 level of Specimen UC lifted up higher than its original horizontal level. While for Specimen 308 GC, the results of deflection illustrate that the original level of Specimen GC remained 309 downwards.

310 According to the observations, for Specimens UC and GC, major crack propagation was 311 extended around the corner loading position, as shown in Figure 13. After that, Specimens 312 UC and GC failed instantly.

313 Finally, Specimen UC completely split into two segments. While for Specimen GC, it was 314 still joined despite the specimen being fully cracked.

315 According to the test results of corner loading, the ductility and resistance of formation of the 316 cracks were slightly improved for the specimens reinforced with geogrid.

317 The bending stresses generated due to the corner loading were resisted by the geogrid layer. 318 This resulted in increasing the carrying-capacity of the geogrid reinforced concrete specimen 319 by about $15 \%$ compared with the references.

320 Also, the time required to cause a $2.5 \mathrm{~mm}$ crack width was increased by about $10 \%$ of the 321 total testing time for the geogrid reinforced concrete specimen. This increase reflects the 322 feasibility of using the geogrid as a crack-formation restraining layer in concrete pavements.

\subsection{Edge loading}

324 The edge applied load versus deflection curves of Specimens UE and GE are presented in 325 Figure 11 (b). At the surface crack width of $2.5 \mathrm{~mm}$, the applied load was $21 \mathrm{kN}$ for Specimen 
UE. For Specimen GE, the total load was $24 \mathrm{kN}$. This increase achieved improvement in the 327 ductility of Specimen GE by about $12 \%$ more than Specimen UE. Also, the fracture energy of 328 Specimen GE is greater than Specimen UE by about 14\%, as shown in Figure 14. Table 4 329 reports test results for Specimens UE and GE.

330 The ductility and fracture energy of the geogrid reinforced concrete specimen were improved. 331 This is due to the geogrid layer, which was embedded in the tension zone of the concrete 332 specimen, resisted the tensile stresses generated in the tension zone.

333 The improvement of flexural behaviour of the concrete specimen reinforced with the geogrid 334 comes from the layer of geogrid working as a bridge layer. This layer acts to transfer the 335 tensile stresses between both tips of the formed cracks.

336 Two structural properties in the geogrid can encourage using the geogrid as the flexural 337 reinforcement in the concrete pavements. These include the high tensile strength and being 338 adequate bonded with the surrounding concrete. As a result, the performance of concrete 339 pavements reinforced with the geogrid can be at the acceptable level during the whole of 340 design stage.

341 The deflection profiles and crack map of Specimens UE and GE are shown in Figure 15. The 342 results of the deflection were collected using two sets of LVDTs, which were $\mathrm{L}_{1}, \mathrm{~L}_{2}$ to $\mathrm{L}_{3}$ and $343 \mathrm{~L}_{1}, \mathrm{~L}_{4}, \mathrm{~L}_{5}$ to $\mathrm{L}_{6}$. From Figure 15 (a), the deflection of Specimens UE and GE was $2.0 \mathrm{~mm}$ and $3441.5 \mathrm{~mm}$, respectively, at the location of LVDT $\mathrm{L}_{1}$, which is located at the edge of the loading 345 of the specimen. This achieved an increase in the load resistance of Specimen GE by about $34625 \%$ more than Specimen UE at the same location. While the deflection of Specimen UE at 347 the locations of LVDTs $\mathrm{L}_{2}$ and $\mathrm{L}_{3}$ was lower than of Specimen GE by about $15 \%$ more. 
348 For the second set of LVDTs, from $\mathrm{L}_{1}$ to $\mathrm{L}_{6}$, the deflection of specimen GE was lower than

349 Specimen UE by about 19\%. Except for the deflection value, which was recorded by LVDT

$350 \mathrm{~L}_{5}$, the deflection of Specimen GE was higher than Specimen UE by about $73 \%$.

351 These unregulated deflection results of Specimens UE and GE, which were recorded by

352 LVDTs, illustrate that, studying the flexural behaviour of concrete pavements reinforced with

353 geogrid and tested under edge loads should be conducted by taking the effect of dowel and tie

354 bars with the adjacent slabs.

355 The failure modes of Specimens UE and GE were different as shown in Figure 16. In general, 356 the geogrid was able to delay and shift formation of cracks in the concrete. For Specimen UE, 357 two cross lines of cracks were formed and extended in the concrete (Figure 16 (a)). The first 358 one was perpendicularly extended toward the boundary of the loading position. The second 359 one was parallel to the boundary of the loading position. These crack lines finally led to 360 separating the specimen into almost four equal segments.

361 For Specimen GE, the main crack line propagated parallel to the boundary of the loading 362 position (Figure 16 (b)). After stopping the testing and lifting Specimen GE from the testing 363 box, there was another microcrack line which extended perpendicular to the main crack line.

364 The cracks in the concrete pavements are considered of one of the main defects which 365 eventually lead to deteriorate the performance of rigid pavement. During the design stage of 366 concrete pavement, the aim of the design of the concrete pavements is mainly how to keep the 367 width of cracks in the concrete tightly closed for a long time.

368 During the monitoring the test, the formation of cracks in the geogrid reinforced concrete 369 specimen took a long time, about $21 \%$, before the $2.5 \mathrm{~mm}$ crack width, failure criteria, took 370 place. This increase in the testing time illustrates the feasibility of using the geogrid as a 371 crack-propagation resisting layer. 
372 As shown in the crack map of the concrete specimen, as shown in Figure 15, a one crack line

373 clearly formed in the concrete specimen reinforced with the geogrid compared with the two crack lines that formed in the unreinforced concrete specimen. This emphasises the role of the geogrid in improving the resistance of the concrete pavement against the formation of cracks.

\subsection{Interior loading}

For Specimens UI and GI, Figure 11 (c) shows the interior applied load versus deflection curves at the loaded area. Where the failure occurred $(2.5 \mathrm{~mm}$ surface crack width), the maximum applied load was $96 \mathrm{kN}$ for Specimen UI. For Specimen GI, the load was $150 \mathrm{kN}$ load. This attained an increase in the ductility of Specimen GI by about $35 \%$ more than Specimen UI. The fracture energy of Specimen GI was increased by about $36 \%$ in comparison with Specimen UI (Figure 17).

For the interior loading test, the effect of geogrid reinforcement in improving the ductility and fracture energy of concrete slab specimen was clearly revealed. This is due to the high proportion of the geogrid layer embedded in the concrete slab contributed in resisting the tensile stresses. In addition, the triaxial geogrid having ribs arranged in multi-direction provides a radial tensile strength at all directions of the slab.

This is why the percentage of the improvement of the ductility and fracture energy of the geogrid reinforced concrete specimen is higher than the other kinds of loading positions.

The deflection and crack map of Specimens UI and GI monitored from LVDTs $\left(\mathrm{L}_{1}\right.$ through $\mathrm{L}_{6}$ ) are shown in Figure 18. According to the reading of LVDT $\mathrm{L}_{1}$ located at a distance of 120 $\mathrm{mm}$ from the edge of the specimen, the recorded deflection was $9 \mathrm{~mm}$ for Specimen UI and 6 $\mathrm{mm}$ for Specimen GI. In the same figure (Figure 18), it can be seen that the surface level of Specimen GI between LVDT $\mathrm{L}_{2}$ and the loading position was deformed as expected. While 
for Specimen UI, the surface level of the specimen lifted from its original datum by about 12

396 mm compared with the datum of Specimen GI.

397 In this loading case, for Specimen UI, the first failure led to the fracture of the concrete 398 specimen occurred at a distance of $125 \mathrm{~mm}$ from the centre of the loading position. While for 399 geogrid reinforced concrete specimen (Specimen GI), the geogrid layer acted as a bridging 400 layer in distributing the tensile stresses and kept the specimen to deflect regularly.

401 Formation of cracks that occurred in this loading case can be grouped into two categories, as 402 pictured in Figure 19. The first group of cracks was initiated and propagated radially outwards from the centre of the loaded area towards the corners and edges of the specimens. This type of cracks mostly occurred in Specimen UI, as shown in Figure 19 (a). In the second group, the cracks were extended as a curve around the load position. This type of cracks completely took place in Specimen UI and partly in Specimen GI, as shown in Figure 19 (a) and (b), 407 respectively. At the end of the testing, few microcracks were observed in Specimen GI and 408 radially extended towards the edges of the specimen.

According to the observations of formation of cracks in the geogrid reinforced concrete specimens, the geogrid can be an intercepting layer against the formation and propagation of 411 cracks in the concrete. The cracks were distributed in multi-directions and within a wide area. 412 Also, the cracks propagated by following longer paths towards the surface and depth of the 413 specimen. As a result, the test time required to form a $2.5 \mathrm{~mm}$ crack width in the concrete was 414 longer, by about $27 \%$, in comparison with the reference specimen.

415 For all loading positions, the geogrid proved that it can improve the flexural behaviour of 416 concrete pavements due to increasing the ductility and fracture energy of the pavement. Also, 417 it can keep the serviceability index of the pavement at the acceptable level for a long time due 418 to maintaining the width of cracks small for a long time. 
419 The improvement of forming resistance of cracks in the geogrid reinforced concrete 420 pavements leads to reducing the funds required for the maintenance of the concrete 421 pavements. In addition, according to the Australian market, the cost of manufacture and 422 installation of the geogrid is lower than the cost required for traditional reinforcement 423 materials. As a result, the geogrid can be a feasible alternative reinforcement material for the 424 rigid pavement applications.

\section{Conclusions}

426 Six concrete slabs, three unreinforced and these reinforced with triaxial geogrid layer, were 427 tested under static loads at three different loading positions: corner, edge and interior of the 428 specimen. The test results obtained illustrate that the geogrid could improve the flexural 429 performance and cracking resistance of the concrete pavements with keeping the side 430 dimension to thickness ratio greater than or equal to 15 , more field investigations are required 431 for concrete slabs reinforced with one or two geogrid. layers and tested under different 432 dimension and support conditions.

433 1. Based on the obtained results of testing the six slabs, the following conclusions are 434 drawn:

435 1. The experimental observations proved that the geogrid reinforcement could contribute 436 to delaying the initiation and propagation of cracks in the concrete, as well as, failure 437 modes are significantly affected by the geogrid before the failure takes place.

2. The side dimension to thickness ratio of slab specimens adopted in this study reflects the behaviour of Portland cement concrete pavements having a thickness between 125 to $180 \mathrm{~mm}$ and a side length between 1875 to $2700 \mathrm{~mm}$. 
3. The fracture energy and ductility of concrete pavements could be improved when reinforcing the concrete pavements with geogrid. So, the geogrid can be considered to improve the design rigid pavements.

4. The geogrid is characterised with high resistance to the tensile stress and corrosion. As a result, the geogrid can be a feasible alternative for steel reinforcement or they can be used as a secondary reinforcement to reduce shrinkage cracks.

5. The geogrid is manufactured from the geosynthetic materials, which are characterised with high resistance of corrosion. So, the cost of maintenance of the concrete pavements is reduced.

\section{Acknowledgement}

The authors present special acknowledgements to Senior Technical Officers Mr Richard Gasser and Mr Cameron Nielson. Also the authors thank all of the staff of the High Bay Laboratory at the School of Civil, Mining, and Environmental Engineering at the University of Wollongong, Australia. Also, the first author would like to thank the Ministry of High Education and Scientific Research of Iraq and the University of Wollongong, Australia for supporting his PhD scholarship.

\section{References}

Abdesssemed, M., Kenai, S., \& Bali, A. (2015). Experimental and numerical analysis of the behavior of an airport pavement reinforced by geogrids. Construction and Building Materials, 94, 547-554. doi: http://dx.doi.org/10.1016/j.conbuildmat.2015.07.037.

Abu-Farsakh, M. Y., \& Chen, Q. (2011). Evaluation of geogrid base reinforcement in flexible pavement using cyclic plate load testing. International Journal of Pavement Engineering, 12(3), 275-288. doi: 10.1080/10298436.2010.549565. 
Abu-Farsakh, M. Y., Akond, I., \& Chen, Q. (2016). Evaluating the performance of geosynthetic-reinforced unpaved roads using plate load tests. International Journal of Pavement Engineering, 17(10), 901-912. doi: 10.1080/10298436.2015.1031131.

Arulrajah, A., Rahman, M. A., Piratheepan, J., Bo, M. W., \& Imteaz, M. A. (2014). Evaluation of interface shear strength properties of geogrid-reinforced construction and demolition materials using a modified large-scale direct shear testing apparatus. Journal of Materials in Civil Engineering, 26(5), 974-982. doi: 10.1061/(ASCE)MT.1943-5533.0000897.

Australian Standard. (2000), Method of testing concrete, Method 11: Determination of the modulus of rupture, Standards Australia Procedures, Technical Committee BD-0.42, AS 1012.11:2000 (Reconfirmed) 2014-10-24, Australia.

Australian Standard. (2009), Concrete Structures. Standards Australia Limited, 1-213. AS 3600:2009 (Incorporating Amendment Nos 1 and 2), Sydney, NSW 2001, Australia.

Australian Standard. (2014). Method 9: Compressive strength tests-Concrete, mortar and grout specimens. Standards Australia Limited, 1-13. AS 1012.9:2014, Sydney, NSW, Australia.

Australian Standard. (2014). Method 3.1: Determination of properties related to the consistency of concrete slump test. Standards Australia Limited, 1-8. AS 1012.3.1:2014, Sydney, NSW, Australia.

Australian Standard. (2005). Geosynthetics-Glossary of terms. Standards Australia Limited, 1-37. AS 3704-2005, Sydney, NSW, Australia. 
Australian Standard. (2000). Methods of testing concrete, Method 11: Determination of the modulus of rupture. Standards Australia Limited, 1-9. AS 1012.11-2000 (Reconfirmed) 2014-10-24, Strathfield, NSW, Australia.

Bažant, Z. P. \& Kazemi, M. T. (1990). Determination of fracture energy, process zone length and brittle number from zone effects with application to rock and concrete. International Journal of Fracture, vol. 44, pp. 111-131.

Boscato, G., \& Russo, S. (2009). Experimental investigation on repair of RC pavements with SFRC. Concr Repair Rehab Retrofitt, 2, 1285-1289.

British Standard. (1996). Geotextiles-Wilde-width tensile test. The International Organization for Standardization (ISO), 1-11. BS EN ISO 10319:1996 E.

Doh, Y. S., Baek, S. H., \& Kim, K. W. (2009). Estimation of relative performance of reinforced overlaid asphalt concretes against reflection cracking due to bending more fracture. Construction and Building Materials, 23(5), 1803-1807. doi: http://dx.doi.org/10.1016/j.conbuildmat.2008.09.027.

Gupta, S., Rao, V. V. L. K., \& Sengupta, J. (2008). Evaluation of Polyester Fiber Reinforced Concrete for use in Cement Concrete Pavement Works. Road Materials and Pavement Design, 9(3), 441-461. doi: 10.1080/14680629.2008.9690127.

Hammons, M. I (1998). Advanced Pavement Design: Finite Element Modeling for Rigid Pavement Joints, Report II: Model Development. U.S. Army Engineer Waterways Experiment Station, 3909 Halls Ferry Road Vicksburg, MS 39180-6199. 
Hanson, J. M., \& Ballinger, C. A. (1974, Revised 1992, Reapproved 1997). Considerations for Design of Concrete Structures Subjected to Fatigue Loading ACI 215R-74. ACI Committee 215, 215R-211 - 215R-224.

Huang, Y. H. 2004, Pavement Analysis and Design, Upper Saddle River, NJ: Pearson/Prentice Hall, C2004, $2^{\text {th }}$ (ed), CH. 4, pp. 147-176.

Karahan, O., Ozbay, E., Atis, C. D., Lachemi, M., \& Hossain, K. M. A. (2016). Effects of milled cut steel fibers on the properties of concrete. KSCE Journal of Civil Engineering. doi: 10.1007/s12205-016-0577-3.

Khodaii, A., \& Fallah, S. (2008). The Effects of Geogrid on Reduction of Reflection Cracking in Asphalt Overlay. Paper presented at the Proceedings of 4th National Conference on Civil Engineering. University of Teheran.

Ling, H. I., \& Liu, Z. (2001). Performance of geosynthetic-reinforced asphalt pavements. Journal of Geotechnical and Geoenvironmental Engineering, 127(2), 177-184. doi: 10.1061/(ASCE)1090-0241(2001)127:2(177).

Maxwell, S., Kim, W., Edil, T. B., \& Benson, C. H. (2005). Effectiveness of geosynthetics in stabilizing soft subgrades. Final Rep. No. 0092-45-15, Dept. of Civil and Environmental Engineering, Univ. of Wisconsin-Madison, Madison, WI.

Meski, F. E., \& Chehab, G. R. (2014). Flexural behavior of concrete beams reinforced with different types of geogrids. Journal of Materials in Civil Engineering, 26(8). doi: influential factor analysis 10.1061/(ASCE)MT.1943-5533.0000920.

O’Flaherty, A., M. (2005). Highways the Location, Design, Construction and Maintenance of Road Pavement. Butterworth-Heinemann, 424-451. 
Rajeshkumar, K., Mahendran, N., \& Gobinath, R. (2010). Experimental Studies on Viability of Using Geosynthetics as Fibers in Concrete. International Journal of Applied Engineering Research, 1(1), 15-28.

Ruiz-Ripoll, L., B. E. Barragán, S. Moro and J. Turmo (2016). Evaluation of the Techniques to Mitigate Early Shrinkage Cracking through an Image Analysis Methodology. Strain, 52(6): 492-502.

Salehian, H., Barros, J. A. O., \& Taheri, M. (2014). Evaluation of the influence of postcracking response of steel fibre reinforced concrete (SFRC) on load carrying capacity of SFRC panels. Construction and Building Materials, 73, 289-304. doi: http://dx.doi.org/10.1016/j.conbuildmat.2014.09.043.

Shankar, A. U. R., \& Suresha, S. N. (2006). Strength Behaviour of Geogrid Reinforced Shedi Soil Subgrade and Aggregate System. Road Materials and Pavement Design, 7(3), 313-330. doi: 10.1080/14680629.2006.9690040.

Siva Chidambaram, R., \& Agarwal, P. (2015a). Flexural and shear behavior of geo-grid confined RC beams with steel fiber reinforced concrete. Construction and Building Materials, 78, 271-280. doi: http://dx.doi.org/10.1016/j.conbuildmat.2015.01.021.

Siva Chidambaram, R., \& Agarwal, P. (2015b). Inelastic behaviour of RC beams with steel fibre and polymer grid confinement. Indian Concrete Journal, 89(4), 83-90.

Siva Chidambaram, R., \& Agarwal, P. (2014). The confining effect of geo-grid on the mechanical properties of concrete specimens with steel fiber under compression and flexure. Construction and Building Materials, 71, 628-637. doi: 10.1016/j.conbuildmat.2014.08.059. 
Sobhan, K., \& Tandon, V. (2011). Mitigating Reflection Cracking in Asphalt Overlays using Geosynthetic Reinforcements. Road Materials and Pavement Design, 9(3/2008), 367387. doi: 10.1080/14680629.2008.969012410.3166/RMPD.9.

Sorelli, L. G., Meda, A., \& Plizzari, G. A. (2006). Steel Fiber Concrete Slabs on Ground: A Structural Matter. ACI Materials Journal, 103(4), 551-558.

Tang, X., Chehab, G. R., \& Palomino, A. (2008). Evaluation of geogrids for stabilising weak pavement subgrade. International Journal of Pavement Engineering, 9, 413-429.

Tang, X., Chehab, G. R., \& Kim, S. (2008). Laboratory study of geogrid reinforcement in Portland cement concrete. Paper presented at the 6th RILEM International Conference on Cracking in Pavements, Chicago, IL.

Wang, W., Sheikh, M. N., \& Hadi, M. N. S. (2015). Axial compressive behaviour of concrete confined with polymer grid. Materials and Structures, 1-17. doi: 10.1617/s11527-0150761-9.

Yoo, D. Y., Lee, J. Y., Shin, H. O., \& Yoon, Y. S. (2015). Enhancing cracking resistance of ultra-high-performance concrete slabs using steel fibres. Magazine of Concrete Research, 67(10), 487-495. doi: 10.1680/macr.14.00116.

Zofka, A., Maliszewski, M., \& Maliszewska, D. (2016). Glass and carbon geogrid reinforcement of asphalt mixtures. Road Materials and Pavement Design, 1-20. doi: 10.1080/14680629.2016.1266775. 
571 Table 1. Physical and mechanical properties of triaxial geogrid

572 Table 2. Test matrix

573 Table 3. Mix proportion

574 Table 4. Experimental results

575

576

577

578

579

580

581

582

583

584

585

586

587

588

589

590 


\section{List of Figures}

592 Figure 1. Triaxial geogrid. (a) Machine Direction (MD). (b) Cross Machine Direction (CMD)

593 Figure 2. Testing triaxial geogrid samples. (a) The geogrid sample in the machine direction

594 (MD). (b) The geogrid sample in the cross machine direction (CMD)

595 Figure 3. Tensile loads versus strain of triaxial geogrid samples in the machine direction 596 (MD) and cross machine direction (CMD)

597 Figure 4. Configurations of concrete slab specimens. (a) Specimen UC. (b) Specimen UE. (c) 598 Specimen UI. (d) Specimen GC. (e) Specimen GE. (f) Specimen GI

599 Figure 5. Dimensions of the recycled rubber

600 Figure 6. Timber formworks for (a) Unreinforced concrete specimens. (b) Geogrid reinforced 601 concrete specimens

602 Figure 7. Steel testing box

603 Figure 8. Checking the appearance of the concrete cover of geogrid reinforced concrete 604 specimens. (a) Before testing. (b) After testing

605 Figure 9. Pictures and configuration of unreinforced and geogrid reinforced concrete 606 specimens. (a) Corner loading configuration. (b) Edge loading configuration. (c) Interior 607 loading configuration. (d) LVDTs locations of the corner loading. (e) LVDTs locations of the 608 edge loading. (f) LVDTs locations of the interior loading

609 Figure 10. Recycled rubber. (a) Preparing two layers of recycled rubber. (b) Placing two 610 layers of recycled rubber beneath the specimen

611 Figure 11. Corner, edge, and interior applied load versus deflection at the loaded area of 612 unreinforced and geogrid reinforced concrete specimens. (a) Specimens UC and GC. (b) 613 Specimens UE and GE. (c) Specimens UI and GI

614 Figure 12. Deflection of Specimens UC and GC at the position of LVDTs for $\mathrm{L}_{1}$ through $\mathrm{L}_{4}$

615 Figure 13. Failure modes of corner loading. (a) Unreinforced concrete Specimen UC. (b) 616 Reinforced concrete Specimen GC 
617 Figure 14. Fracture energy versus percentage of fracture loads for unreinforced and geogrid 618 reinforced slab specimens, Edge loading

619 Figure 15. Deflection of Specimens UE and GE at the position of LVDTs. (a) For $\mathrm{L}_{1}, \mathrm{~L}_{4}, \mathrm{~L}_{5}$, 620 and $\mathrm{L}_{6}$. (b) For $\mathrm{L}_{1}, \mathrm{~L}_{2}$, and $\mathrm{L}_{3}$

621 Figure 16. Failure modes of edge loading. (a) Unreinforced concrete Specimen UE. (b)

622 Reinforced concrete Specimen GE

623 Figure 17. Fracture energy versus percentage of fracture loads for unreinforced and geogrid 624 reinforced slab specimens, Interior loading

625 Figure 18. Displacement of Specimens UI and GI at the position of LVDTs for $\mathrm{L}_{1}, \mathrm{~L}_{2}, \mathrm{~L}_{3}, \mathrm{~L}_{4}$, $626 \mathrm{~L}_{5}$, and $\mathrm{L}_{6}$

627 Figure 19. Failure modes of interior loading. (a) Unreinforced concrete Specimen UI. (b)

628 Reinforced concrete Specimen GI

629

630

631

632

633

634

635

636

637

638

639

640

641

642 
643 Table 1. Physical and mechanical properties of triaxial geogrid.

\begin{tabular}{|c|c|c|c|}
\hline & Property (unit) & Results & Remarks \\
\hline \multirow{8}{*}{ 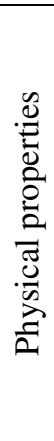 } & Geosynthetic products & Triaxial geogrid & \multirow{8}{*}{$\begin{array}{l}\text { measured by } \\
\text { digital vernier } \\
\text { calliper }\end{array}$} \\
\hline & material & Polypropylene composite & \\
\hline & Aperture shape & Triangular & \\
\hline & Rib pitch (mm) & 40 Longitudinal $\times 40$ & \\
\hline & MidRib depth (mm) & 1.53 & \\
\hline & MidRib width (mm) & 1.55 & \\
\hline & Rib length (mm) & 34 & \\
\hline & Nodal thickness (mm) & 3.94 & \\
\hline \multirow{10}{*}{ 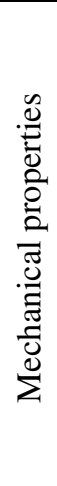 } & Nominal gauge length, MD*/CMD** (mm) & $185 / 130$ & \multirow{10}{*}{$\begin{array}{c}\text { determined using } \\
\text { AS 3704-2005 } \\
\text { and EN ISO } \\
\text { 10319:1996 }\end{array}$} \\
\hline & Specimen width, MD/CMD (mm) & $275 / 250$ & \\
\hline & Maximum tensile load, MD/CMD (kN) & $5.2 / 6.5$ & \\
\hline & Strain at maximum tensile load, MD/CMD (\%) & $9.80 / 13.34$ & \\
\hline & Tensile strength, MD/CMD (kN/m) & $18.82 / 26.11$ & \\
\hline & Tensile strength at $2 \%$ strain, $\mathrm{MD} / \mathrm{CMD}(\mathrm{kN} / \mathrm{m})$ & $7.0 / 7.0$ & \\
\hline & Tensile strength at 5\% strain, MD/TD (kN/m) & $12.7 / 13.0$ & \\
\hline & at $2 \%$ strain $\mathrm{MD} / \mathrm{CMD}$ & $3.50 / 2.50$ & \\
\hline & at $5 \%$ strain $\mathrm{MD} / \mathrm{CMD}$ & $1.70 / 3.44$ & \\
\hline & at $10 \%$ strain $\mathrm{MD} / \mathrm{CMD}$ & $2.62 / 2.20$ & \\
\hline
\end{tabular}

MD and CMD are Machine Direction and Cross Machine Direction of the triaxial geogrid, respectively.

644

645

646

647

648

649

650

651

652

653

654 
Table 2. Test matrix.

\begin{tabular}{|c|c|c|c|c|c|}
\hline Category designation & $\begin{array}{l}\text { Loading } \\
\text { position }\end{array}$ & $\begin{array}{l}\text { Specimen } \\
\text { label }\end{array}$ & $\begin{array}{l}\text { Dimensions } \\
(\mathrm{mm})\end{array}$ & Reinforcement & Support \\
\hline \multirow{3}{*}{$\begin{array}{l}\text { Unreinforced concrete } \\
\text { specimens (reference) }\end{array}$} & Corner & $\mathrm{UC}$ & & None & \multirow{6}{*}{$\begin{array}{c}\text { Recycled } \\
\text { rubber }\end{array}$} \\
\hline & Edge & UE & $900 \times 900 \times 60$ & None & \\
\hline & Interior & UI & & None & \\
\hline \multirow{3}{*}{$\begin{array}{l}\text { Geogrid reinforced } \\
\text { concrete specimens }\end{array}$} & Corner & GC & \multirow{3}{*}{$900 \times 900 \times 60$} & Triaxial geogrid & \\
\hline & Edge & GE & & Triaxial geogrid & \\
\hline & Interior & GI & & Triaxial geogrid & \\
\hline
\end{tabular}

656

657

658

659

660

661

662

663

664

665

666

667

668

669

670

671

672 
673 Table 3. Mix proportion.

\begin{tabular}{ccccccccc}
\hline $\begin{array}{c}\text { Cement } \\
\left(\mathrm{kg} / \mathrm{m}^{3}\right)\end{array}$ & $\begin{array}{c}\text { Flay ash } \\
\left(\mathrm{kg} / \mathrm{m}^{3}\right)\end{array}$ & $\begin{array}{c}\text { Slag } \\
\left(\mathrm{kg} / \mathrm{m}^{3}\right)\end{array}$ & $\begin{array}{c}\text { Aggregate } \\
(10 \mathrm{~mm} \\
\text { size })\left(\mathrm{kg} / \mathrm{m}^{3}\right)\end{array}$ & $\begin{array}{c}\text { Coarse } \\
\text { sand } \\
\left(\mathrm{kg} / \mathrm{m}^{3}\right)\end{array}$ & $\begin{array}{c}\text { Fine } \\
\text { sand } \\
\left(\mathrm{kg} / \mathrm{m}^{3}\right)\end{array}$ & $\begin{array}{c}\text { Water-reducing } \\
\text { admixture }(\text { WRDA- } \\
\text { PN20) }\left(1 / \mathrm{m}^{3}\right)\end{array}$ & $\begin{array}{c}\text { Water } \\
\left(1 / \mathrm{m}^{3}\right)\end{array}$ & $\begin{array}{c}\text { w/c } \\
169\end{array}$ \\
\hline 68 & 102 & 820 & 332 & 664 & 1525 & 153.5 & 0.45 \\
\hline
\end{tabular}

674

675

676

677

678

679

680

681

682

683

684

685

686

687

688

689

690

691

692 
Table 4. Experimental results.

\begin{tabular}{cccccccc}
\hline $\begin{array}{c}\text { Specimen } \\
\text { label }\end{array}$ & $\mathrm{P}_{\text {ref. }}(\mathrm{kN})$ & $\mathrm{P}_{\mathrm{AL}}(\mathrm{kN})$ & $\Delta_{\text {ref. }}(\mathrm{mm})$ & $\Delta_{\mathrm{AL}}(\mathrm{mm})$ & $\begin{array}{c}\left\{\left(\mathrm{P}_{\mathrm{AL}} / \mathrm{P}_{\text {ref. }}\right)-1\right\} \times 100 \\
(\%)\end{array}$ & $\begin{array}{c}\text { Ductility } \\
(\%)\end{array}$ & $\begin{array}{c}\text { Fracture energy } \\
(\%)\end{array}$ \\
\hline UC & 17.0 & ------ & 15 & ----- & ----- & ---- & 7 \\
UE & 21.0 & ----- & 14 & ----- & ---- & ---- & 12.6 \\
UI & 96.0 & ----- & 32 & ----- & ----- & ---- & 31.4 \\
GC & ----- & 20 & ----- & 14 & 17 & 10 & 8.2 \\
GE & ---- & 24 & ----- & 15 & 14 & 12 & 14.4 \\
GI & ----- & 150 & ----- & 33 & 56 & 35 & 49.05 \\
\hline
\end{tabular}

$\mathrm{P}_{\text {ref. }}$ and $\mathrm{P}_{\mathrm{AL}}$ are the total applied loads of unreinforced and geogrid reinforced concrete specimens, respectively, at a 2.5 surface crack width occurred. $\Delta_{\text {ref. }}$ and $\Delta_{\mathrm{AL}}$ are the deflection of unreinforced and geogrid reinforced concrete specimens at the centre of the applied load, respectively, at a 2.5 surface crack width occurred.

694

695

696

697

698

699

700

701

702

703

704

705

706

707

708

709 


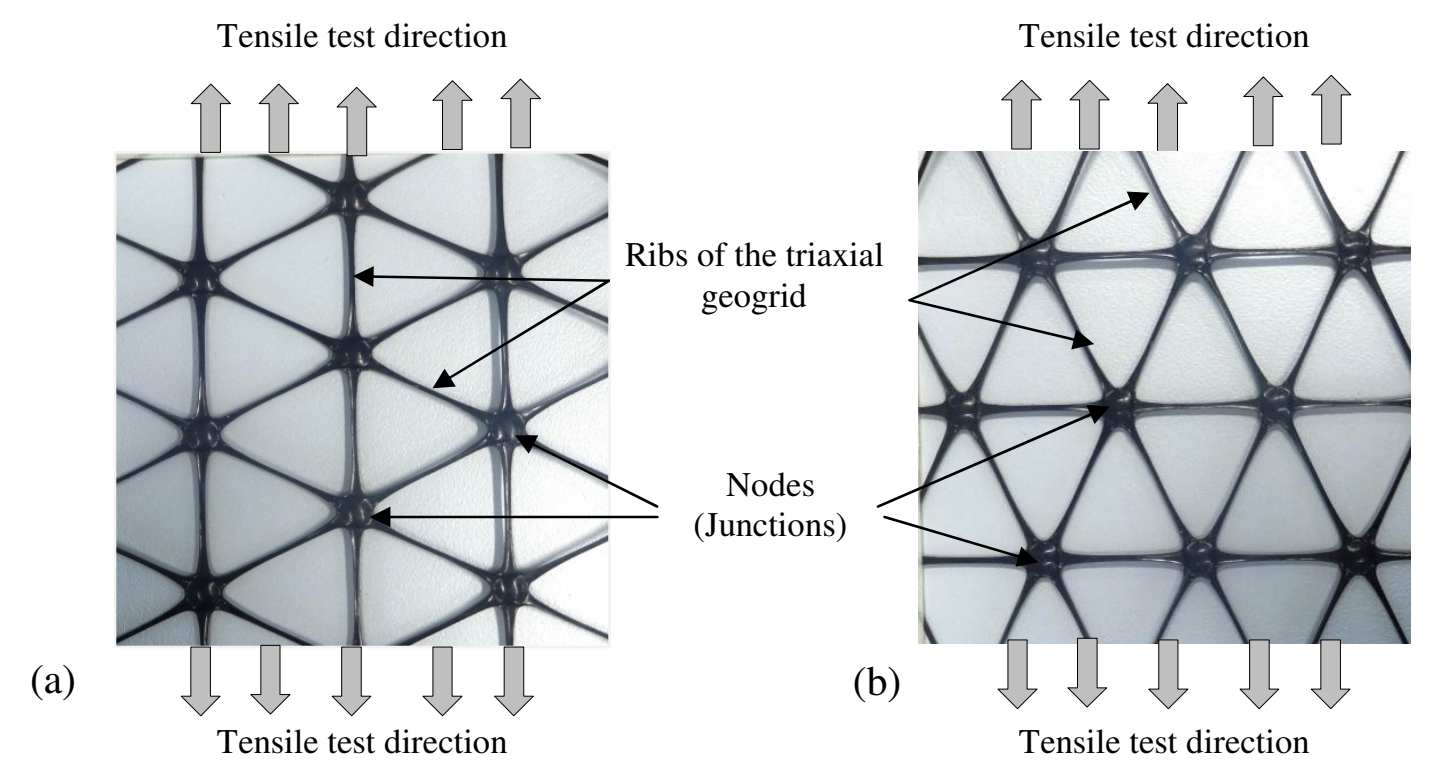

Figure 1. Triaxial geogrid. (a) Machine Direction (MD). (b) Cross Machine Direction (CMD). 


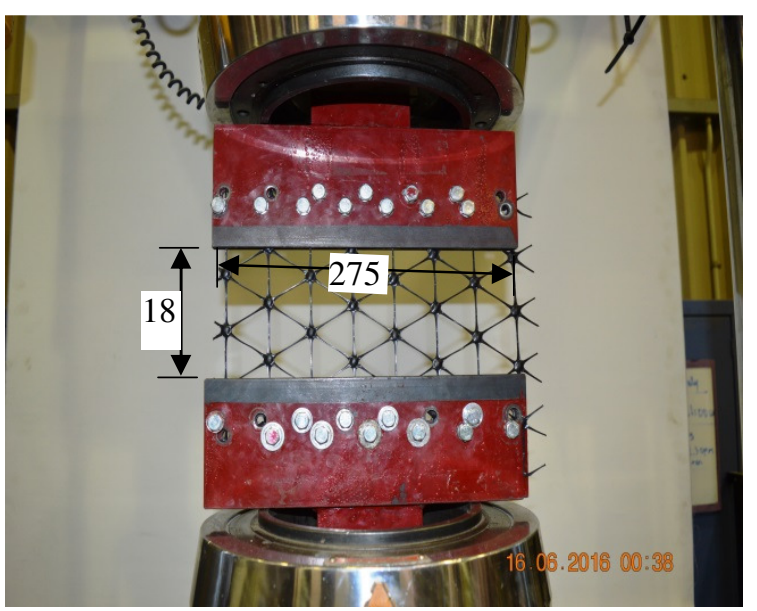

(a)

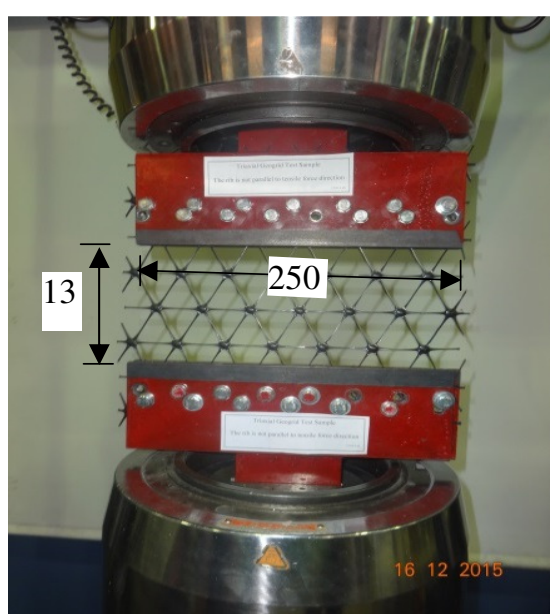

(b)

(All dimensions in millimetres)

Figure 2. Testing triaxial geogrid samples. (a) The geogrid sample in the machine direction (MD). (b) The geogrid sample in the cross machine direction (CMD). 


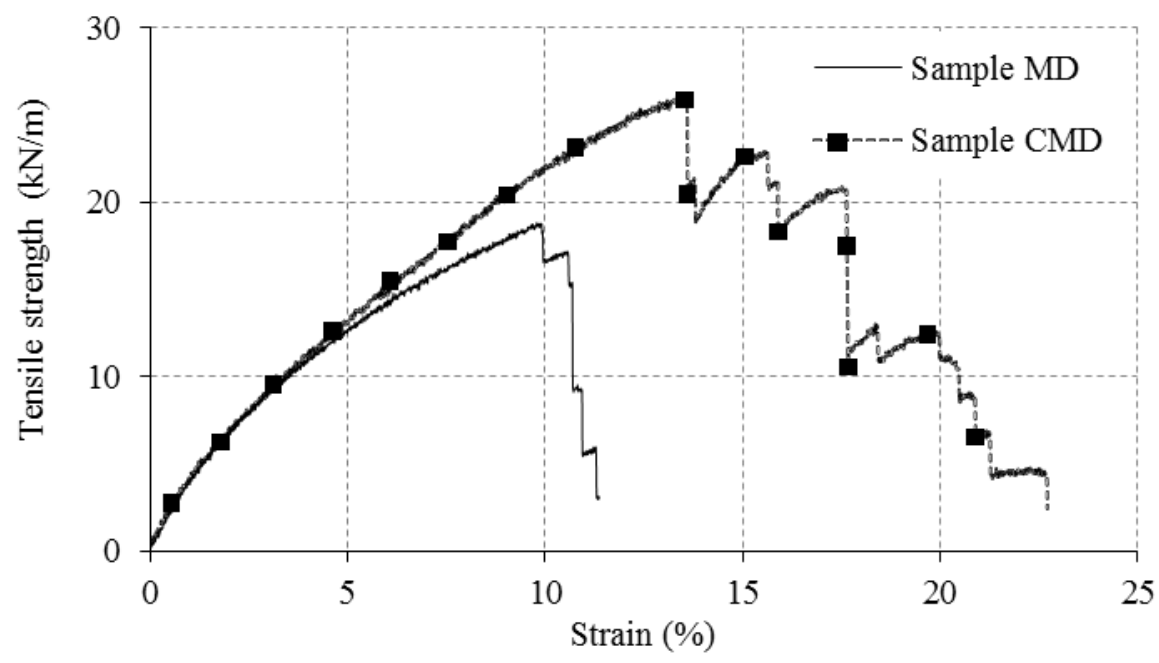

Figure 3. Tensile loads versus strain of triaxial geogrid samples in the machine direction (MD) and cross machine direction (CMD). 


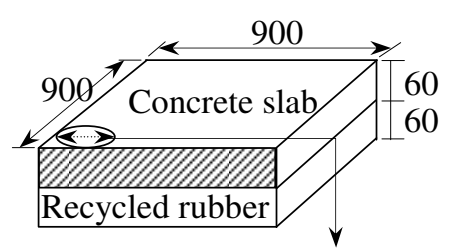

$140 \mathrm{~mm}$ diameter loaded area

(a)

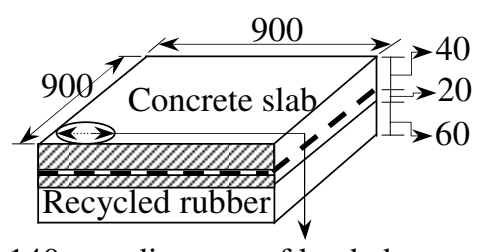

$140 \mathrm{~mm}$ diameter of loaded area

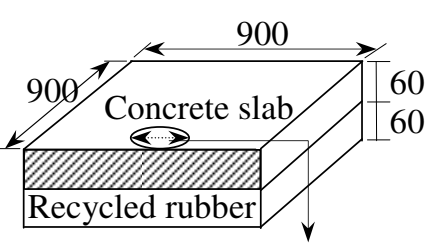

$140 \mathrm{~mm}$ diameter of loaded area

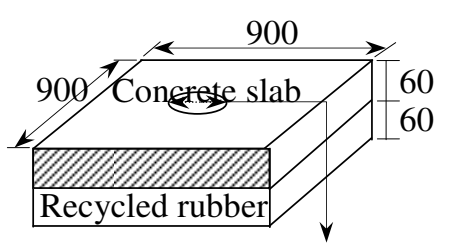

$140 \mathrm{~mm}$ diameter of loaded area

(b)

(c)

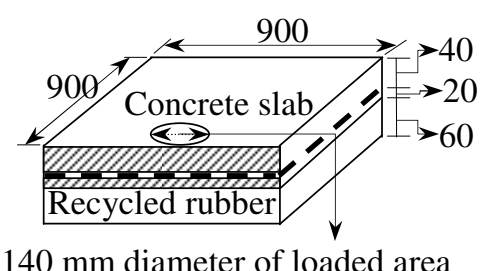

(e)

(f)

(All dimensions in millimetres)

Figure 4. Configurations of concrete slab specimens. (a) Specimen UC. (b) Specimen UE. (c) Specimen UI. (d) Specimen GC. (e) Specimen GE. (f) Specimen GI. 


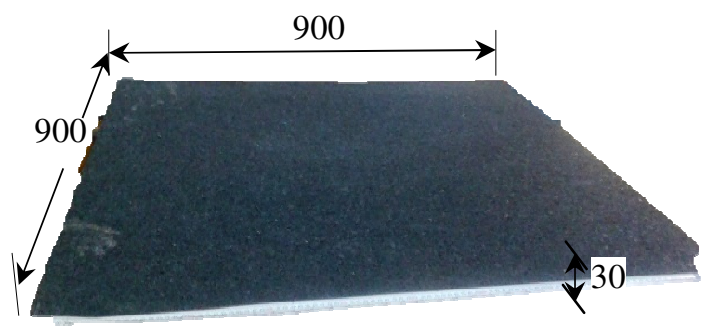

(All dimensions in millimetres)

Figure 5. Dimensions of the recycled rubber.

762

763

764

765

766

767

768

769

770

771

772

773

774

775

776 


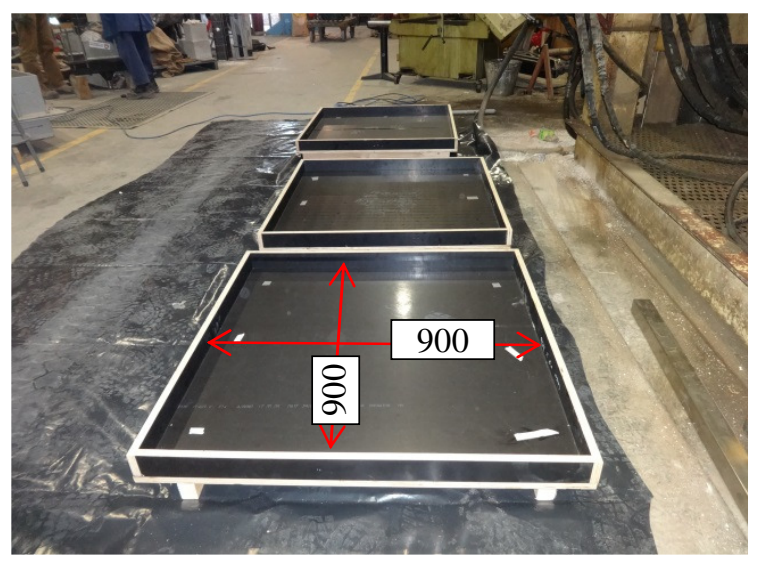

(a)

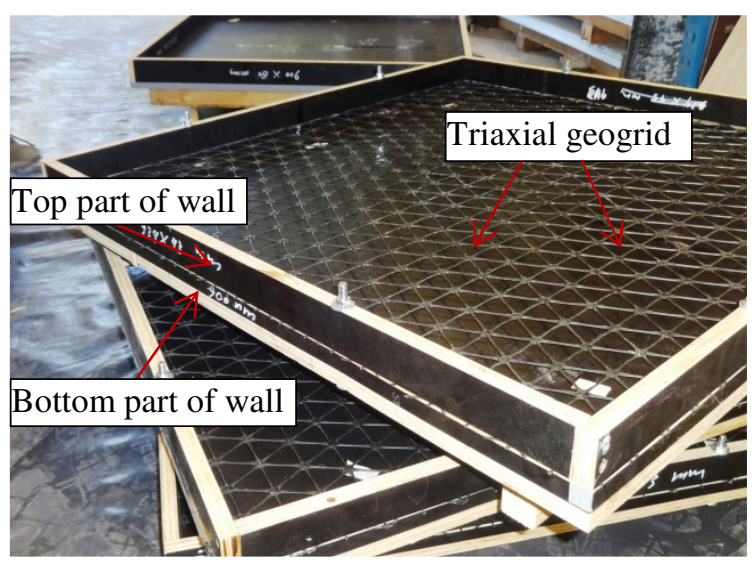

(b)

(All dimensions in millimetres)

Figure 6. Timber formworks for (a) Unreinforced concrete specimens. (b) Geogrid reinforced concrete specimens. 


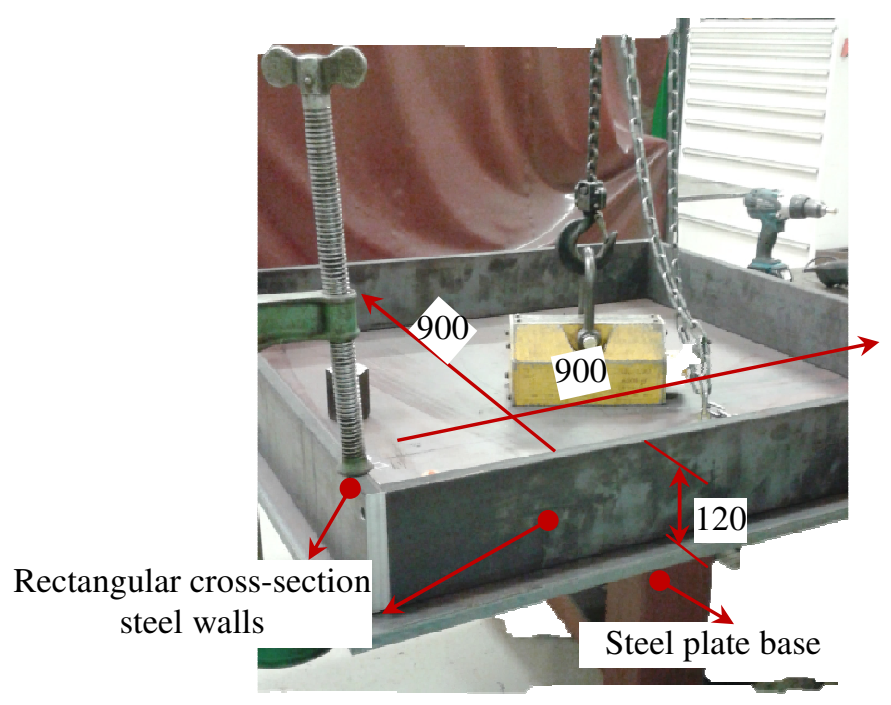

(All dimensions in millimetres)

Figure 7. Steel testing box.

791

792

793

794

795

796

797

798

799

800

801

802 

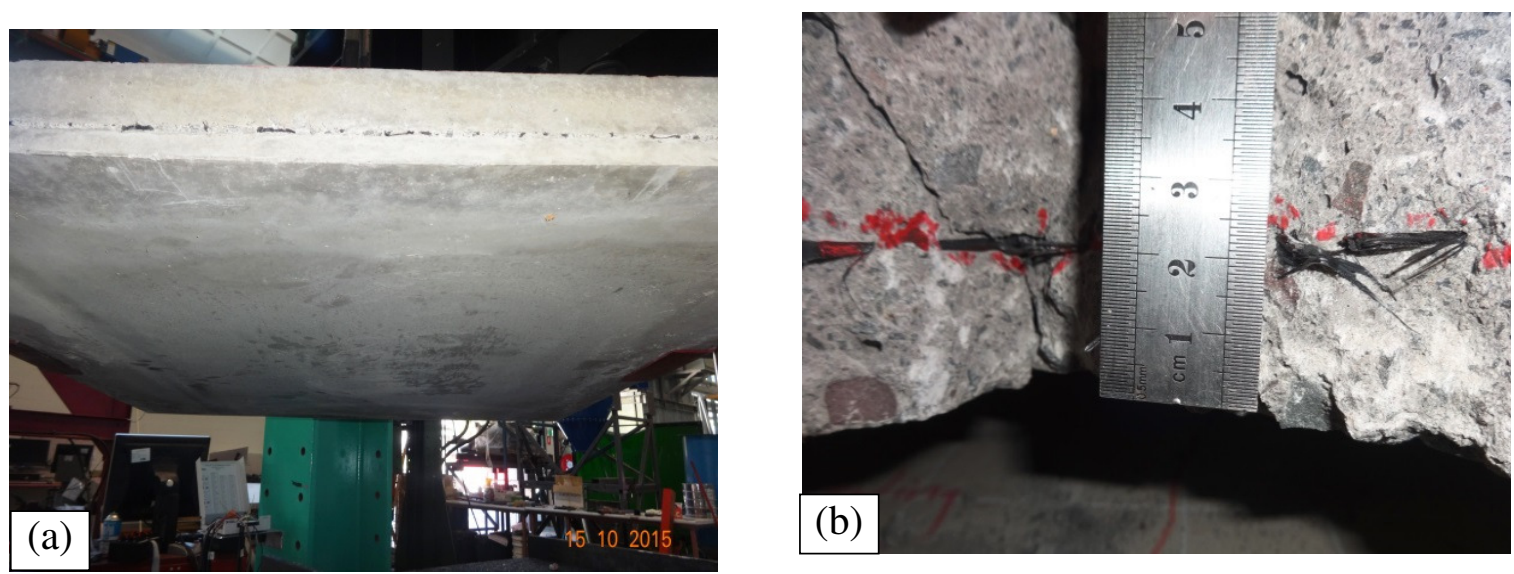

Figure 8. Checking the appearance of the concrete cover of geogrid reinforced concrete specimens. (a) Before testing. (b) After testing.

803

804

805

806

807

808

809

810

811

812

813

814

815

816 


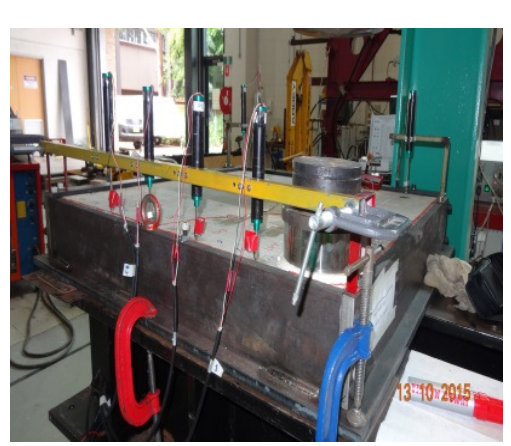

(a)

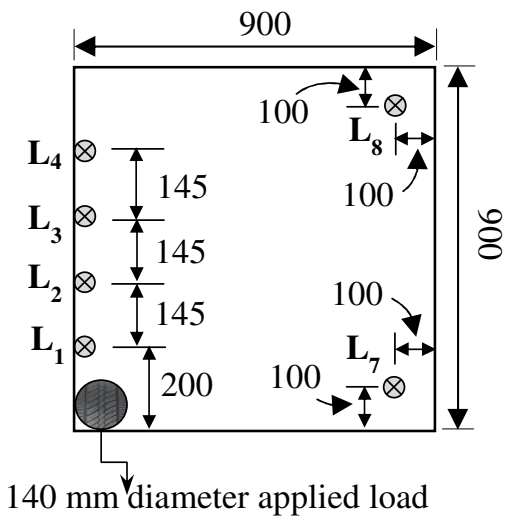

(d)

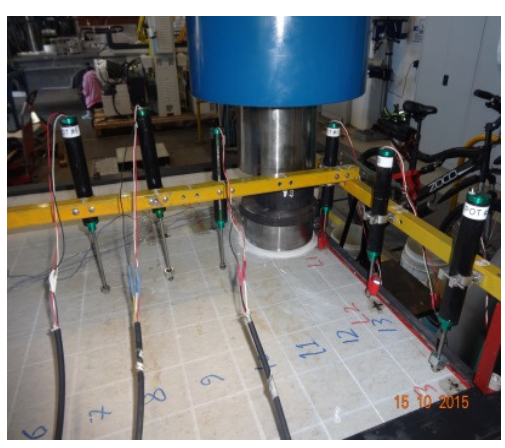

(b)

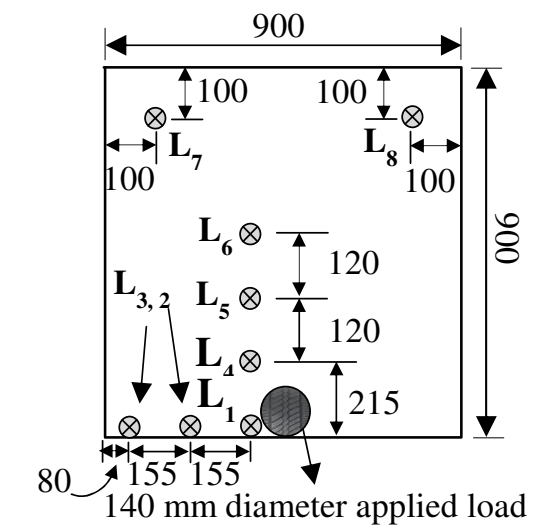

(e)

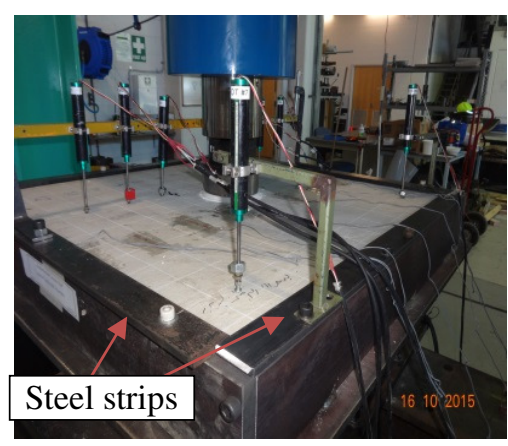

(c)

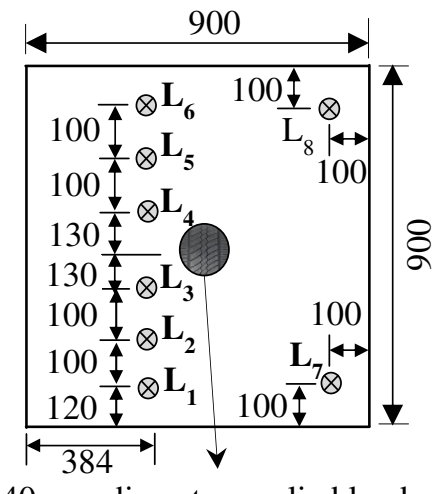

$140 \mathrm{~mm}$ diameter applied load

(f)

(All dimensions in millimetres)

Figure 9. Pictures and configuration of unreinforced and geogrid reinforced concrete specimens. (a) Corner loading configuration. (b) Edge loading configuration. (c) Interior loading configuration. (d) LVDTs locations of the corner loading. (e) LVDTs locations of the edge loading. (f) LVDTs locations of the interior loading. 


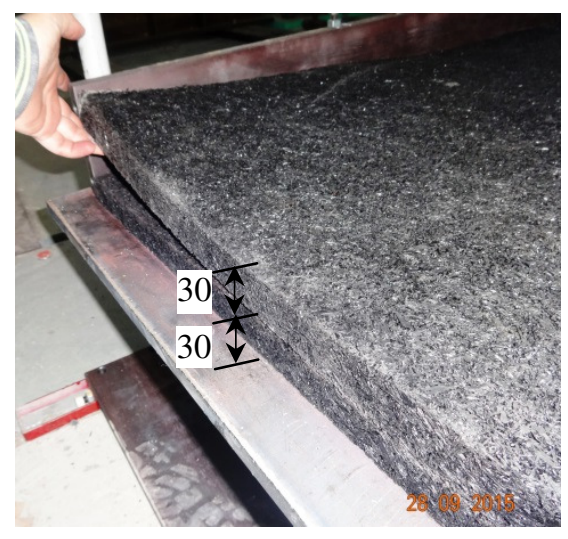

(a) Recycled rubber preparation.

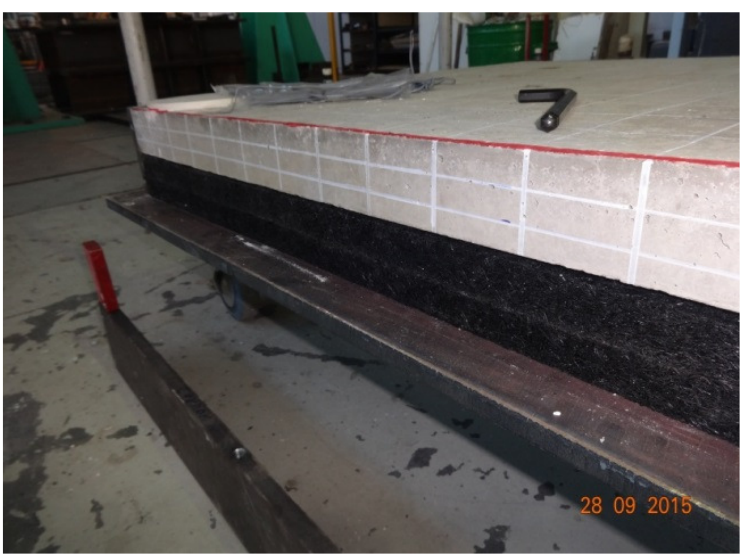

(b) Two recycled rubber layers beneath specimen.

(All dimensions in millimetres)

Figure 10. Recycled rubber. (a) Preparing two layers of recycled rubber. (b) Placing two layers of recycled rubber beneath the specimen.

826

827

828

829

830

831

832

833

834 


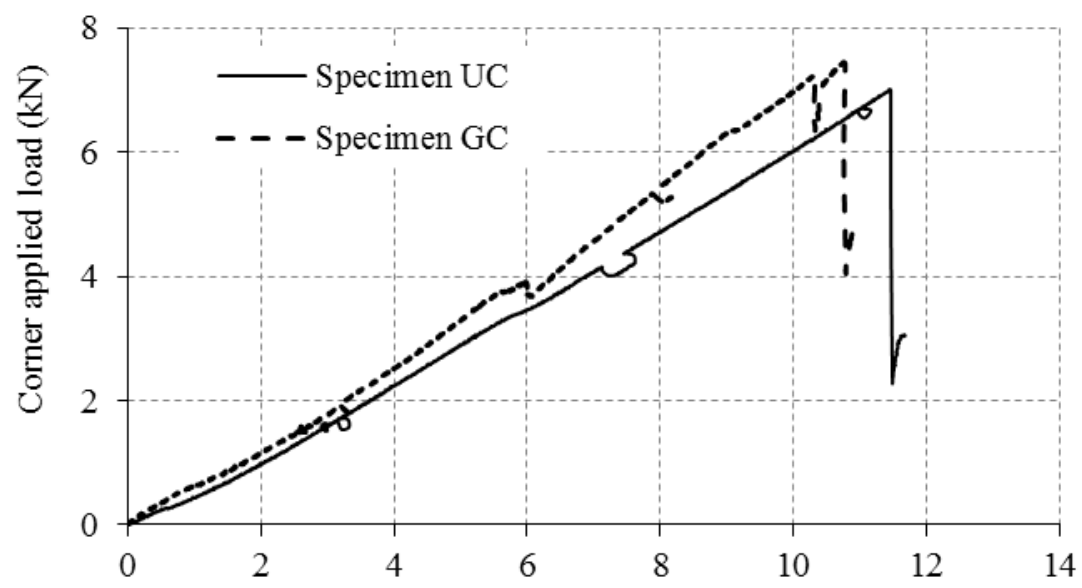

(a)

Deflection at loaded area $(\mathrm{mm})$

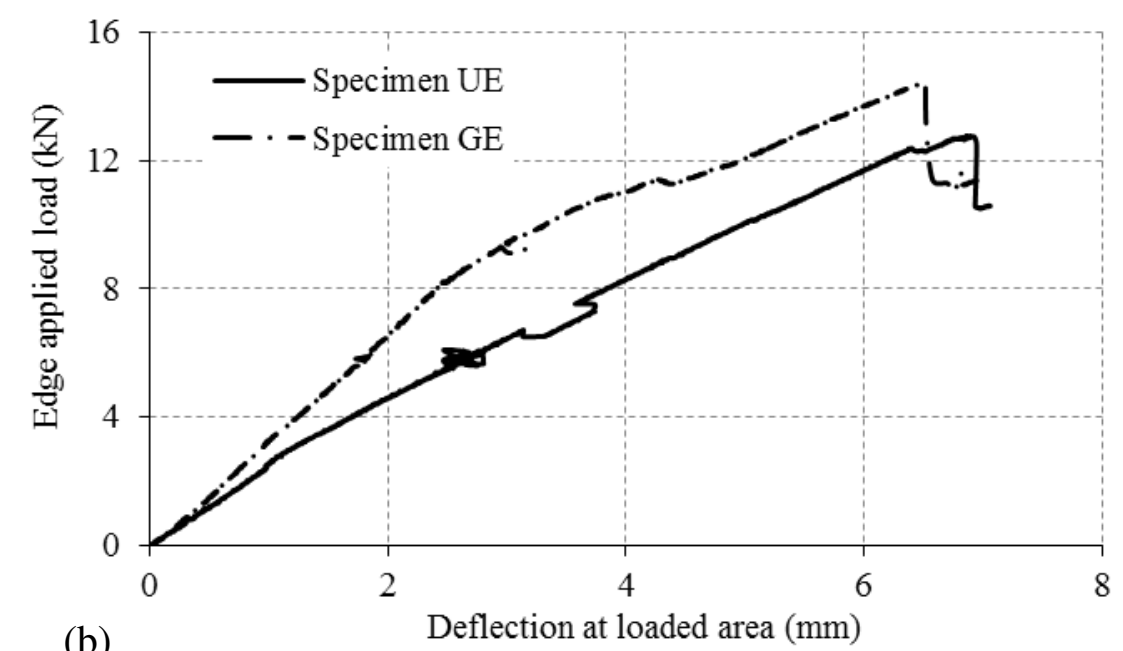

(b)

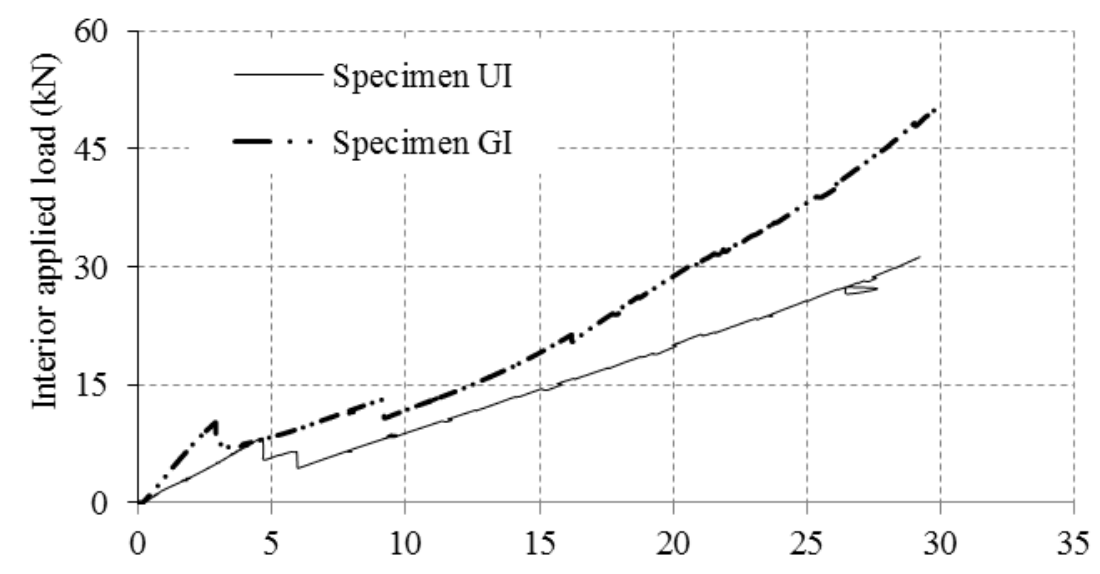

(c)

Deflection at loaded area $(\mathrm{mm})$

Figure 11. Corner, edge, and interior applied load versus deflection at the loaded area of unreinforced and geogrid reinforced concrete specimens. (a) Specimens UC and GC. (b) Specimens UE and GE. (c) Specimens UI and GI. 

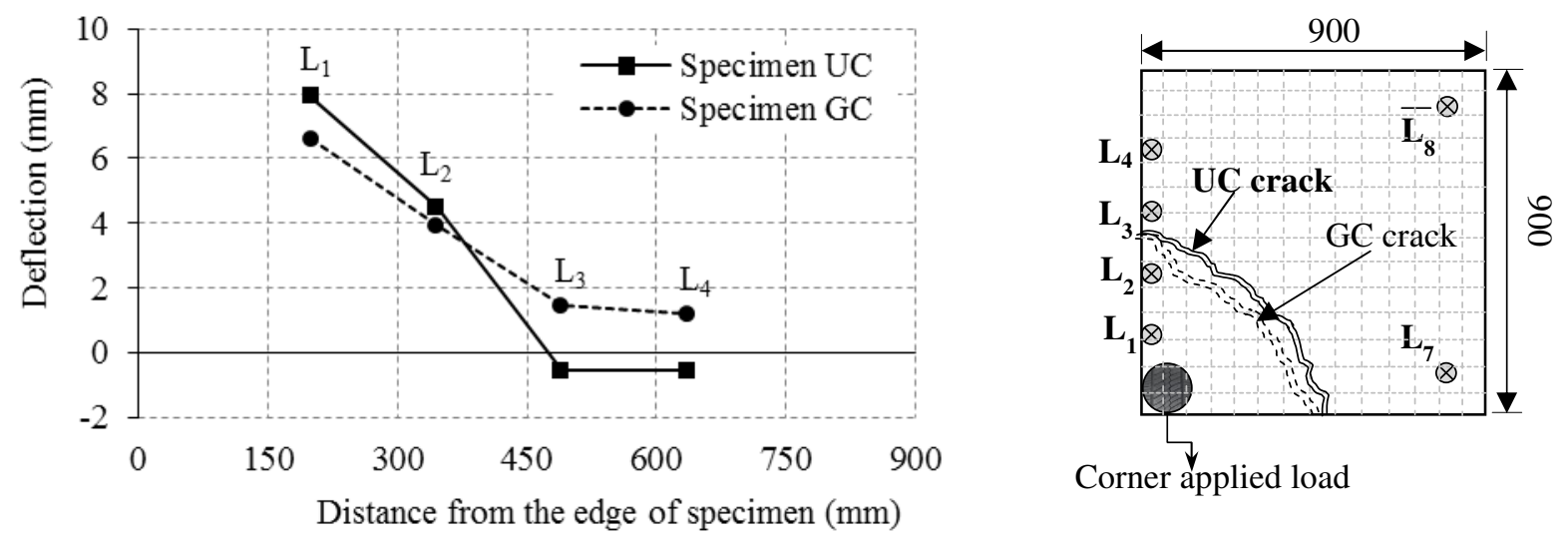

Figure 12. Deflection of Specimens UC and GC at the position of LVDTs for $\mathrm{L}_{1}$ through $\mathrm{L}_{4}$.

837

838

839

840

841

842

843

844

845

846

847

848

849

850

851 


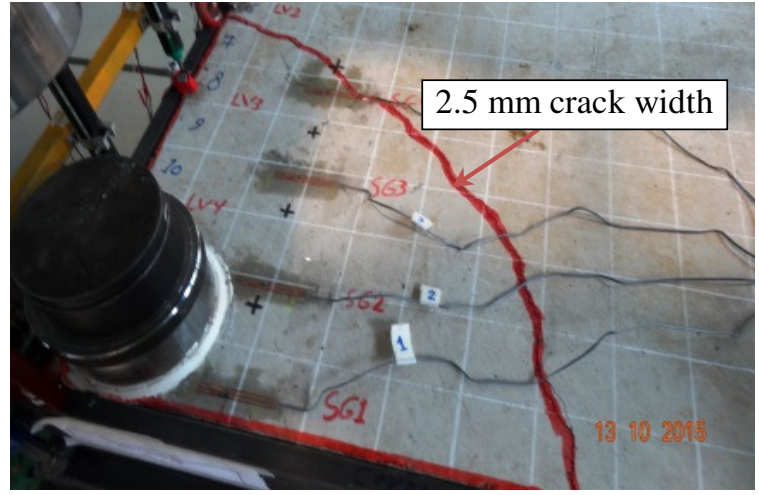

(a) Specimen UC

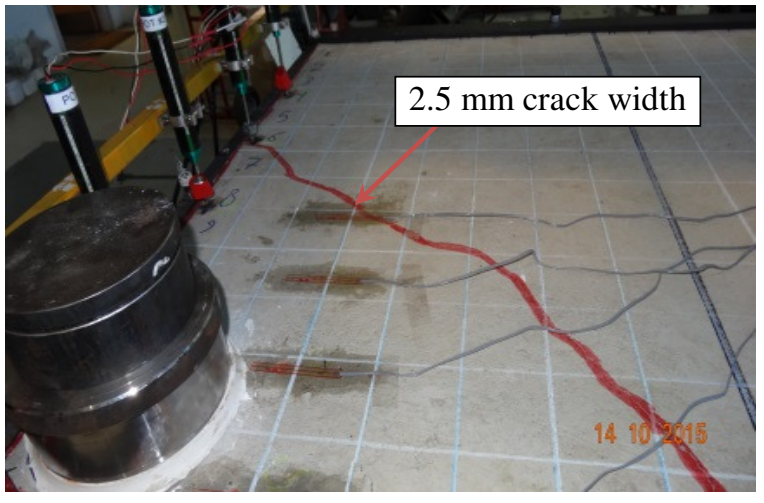

(b) Specimen GC

Figure 13. Failure modes of corner loading. (a) Unreinforced concrete Specimen UC. (b) Reinforced concrete Specimen GC. 


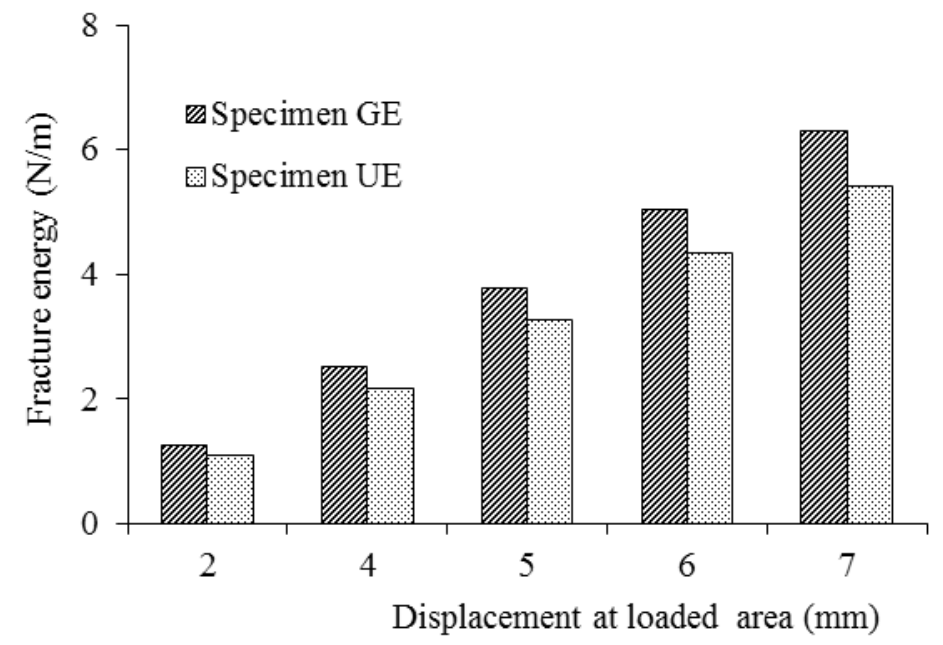

Figure 14. Fracture energy versus percentage of fracture loads for unreinforced and geogrid reinforced slab specimens, Edge loading. 


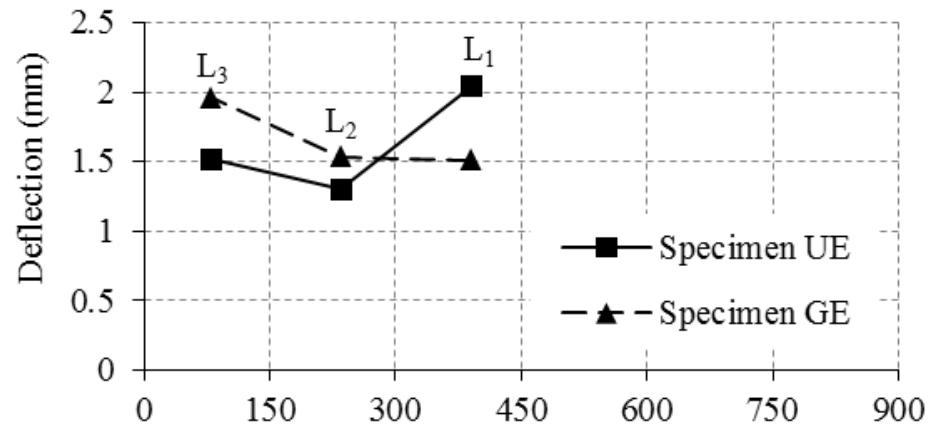

(b) Distance from the edge of specimen ( $\mathrm{mm}$ )

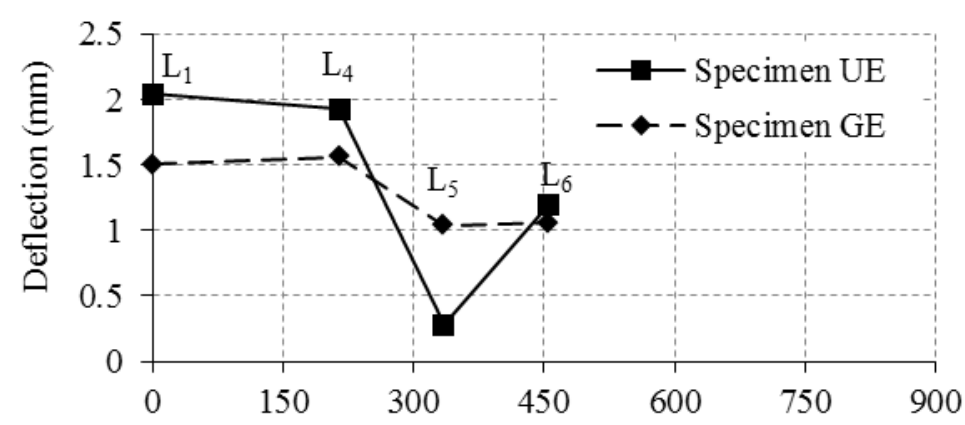

(a) Distance from the edge of specimen ( $\mathrm{mm})$

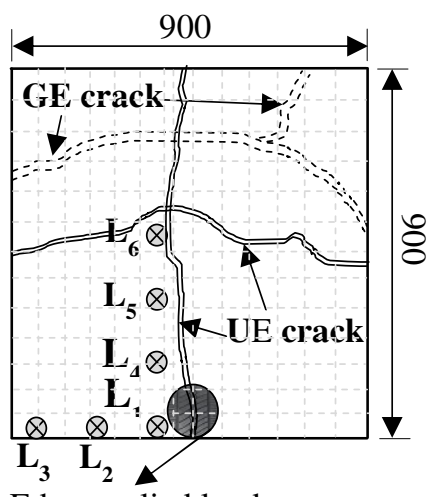

Edge applied load

Figure 15. Deflection of Specimens UE and GE at the position of LVDTs. (a) For $\mathrm{L}_{1}, \mathrm{~L}_{4}, \mathrm{~L}_{5}$, and $\mathrm{L}_{6}$. (b) For $\mathrm{L}_{1}, \mathrm{~L}_{2}$, and $\mathrm{L}_{3}$.

884

885

886

887

888

889 


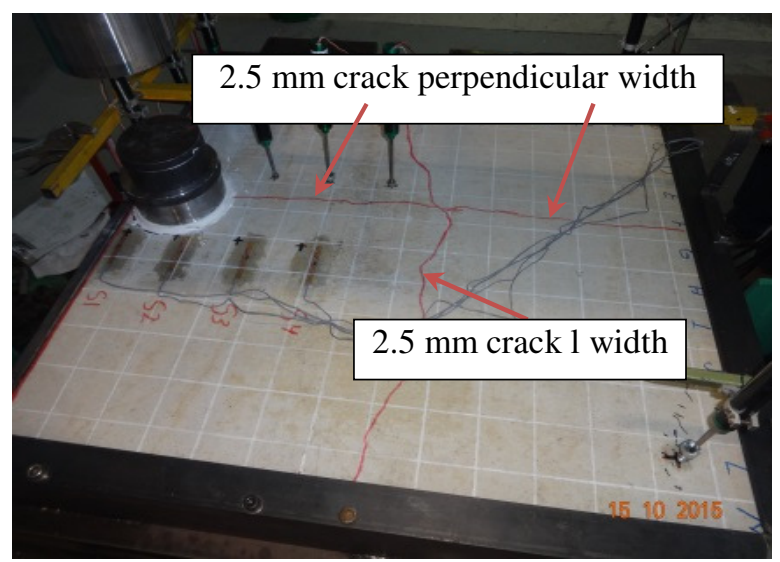

(a) Specimen UE

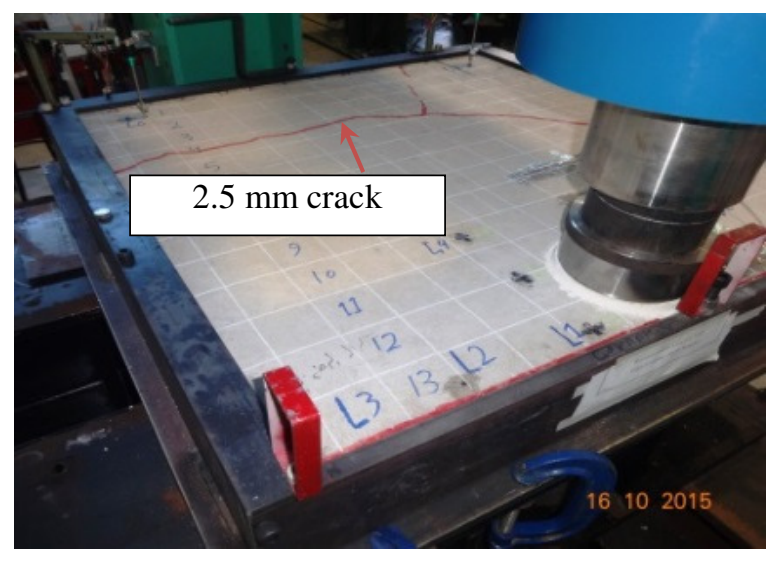

(b) Specimen GE

Figure 16. Failure modes of edge loading. (a) Unreinforced concrete Specimen UE. (b) Reinforced concrete Specimen GE.

891

892

893

894

895

896

897

898

899

900

901

902

903

904 


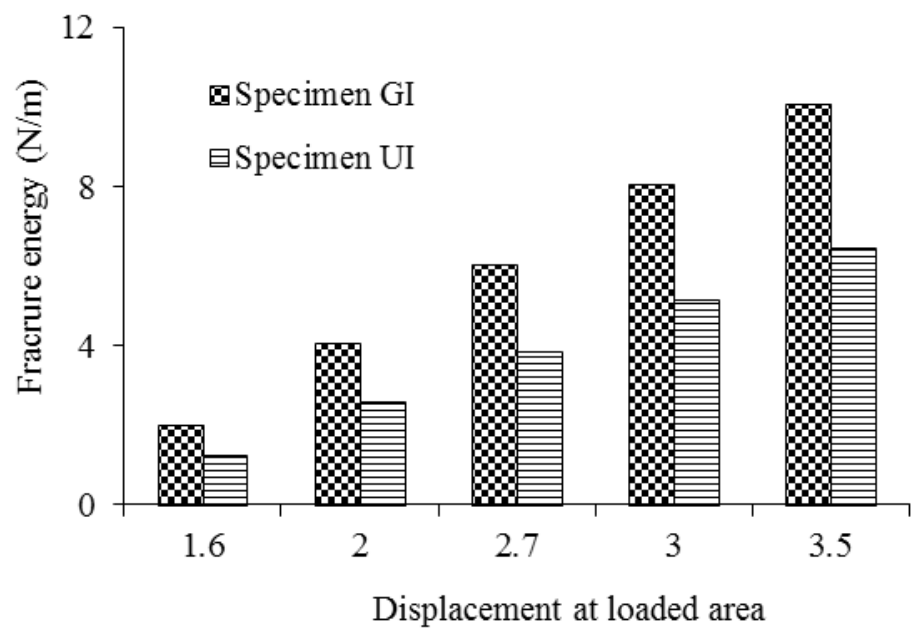

Figure 17. Fracture energy versus percentage of fracture loads for unreinforced and geogrid reinforced slab specimens, Interior loading.

905

906

907

908

909

910

911

912

913

914

915

916

917

918 


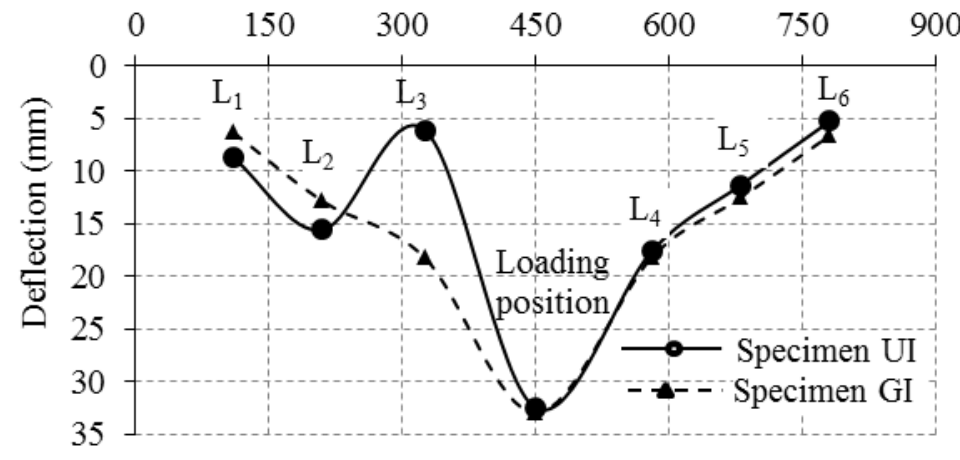

Distance from the edge of specimen (mm)

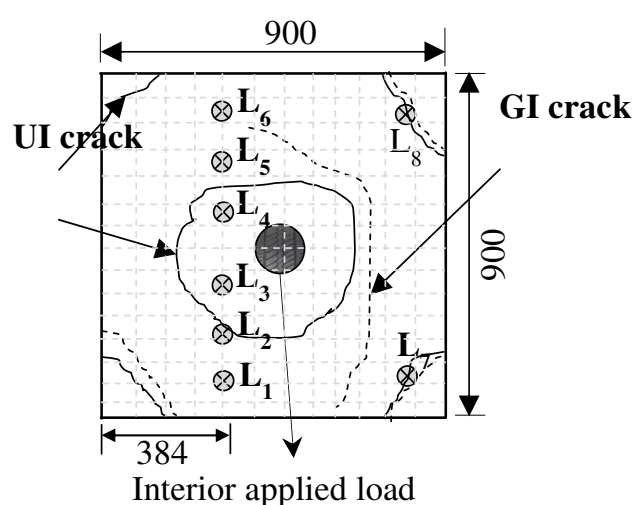

Figure 18. Displacement of Specimens UI and GI at the position of LVDTs for $\mathrm{L}_{1}, \mathrm{~L}_{2}, \mathrm{~L}_{3}, \mathrm{~L}_{4}$, $\mathrm{L}_{5}$, and $\mathrm{L}_{6}$. 


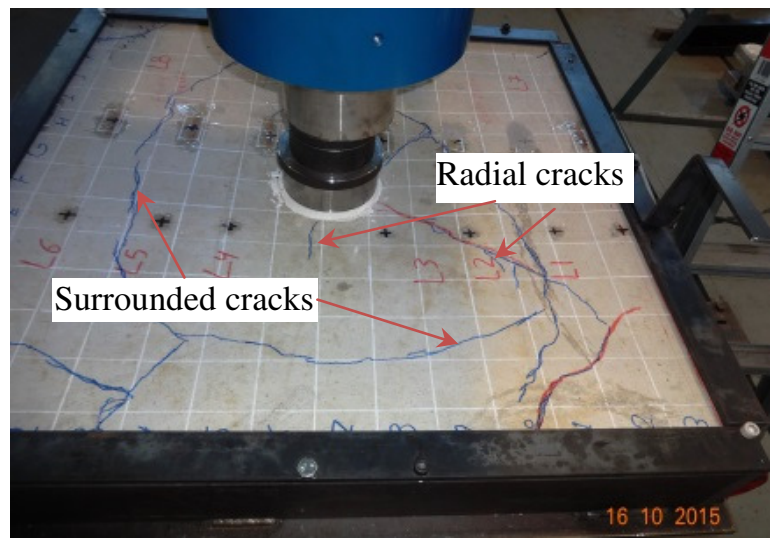

(a) Specimen UI

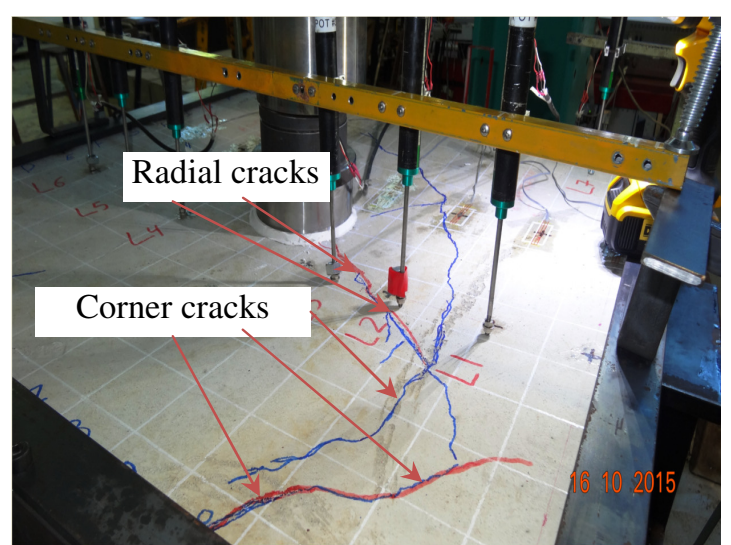

(b) Specimen GI

Figure 19. Failure modes of interior loading. (a) Unreinforced concrete Specimen UI. (b) Reinforced concrete Specimen GI.

934

935

936

937

938

939

940

941

942

943

944

945

946

947 